\title{
TID Environmental Performance Testing In Support of the Mayak Fissile Material Storage Facility
}

\author{
J. E. Tanner \\ H. A. Undem \\ B. A. Roberts \\ J. R. Griggs \\ S. L. Pratt \\ M. H. Smith
}

March 2002

Prepared for and sponsored by the Defense Threat Reduction Agency as Work for Others under U.S. Department of Energy Contract DE-AC06-76RL01830 


\title{
DISCLAIMER
}

This report was prepared as an account of work sponsored by an agency of the United States Government. Neither the United States Government nor any agency thereof, nor Battelle Memorial Institute, nor any of their employees, makes any warranty, express or implied, or assumes any legal liability or responsibility for the accuracy, completeness, or usefulness of any information, apparatus, product, or process disclosed, or represents that its use would not infringe privately owned rights. Reference herein to any specific commercial product, process, or service by trade name, trademark, manufacturer, or otherwise does not necessarily constitute or imply its endorsement, recommendation, or favoring by the United States Government or any agency thereof, or Battelle Memorial Institute. The views and opinions of authors expressed herein do not necessarily state or reflect those of the United States Government or any agency thereof.

\author{
PACIFIC NORTHWEST NATIONAL LABORATORY \\ operated by \\ BATTELLE \\ for the \\ UNITED STATES DEPARTMENT OF ENERGY \\ under Contract DE-AC06-76RL01830
}

This document was printed on recycled paper. 


\title{
TID Environmental Performance Testing In Support of the Mayak Fissile Material Storage Facility
}

\author{
J. E. Tanner \\ H. A. Undem \\ B. A. Roberts \\ J. R. Griggs \\ S. L. Pratt \\ M. H. Smith
}

March 2002

Prepared for and sponsored by the Defense Threat Reduction Agency as Work for Others under U.S. Department of Energy Contract DE-AC06-76RL01830

Pacific Northwest National Laboratory

Richland, Washington 99352 


\section{Executive Summary}

The purpose of the test and evaluation of tamper indicating devices (TIDs) described in this report is to examine existing and commercially available TID technologies for specific use at the Mayak Fissile Material Storage Facility (FMSF). In this respect, TIDs that have been used under best international safeguards practices form a natural testing baseline. TID candidacy is based on TID performance with respect to mutually agreed functional, operational, and security requirements for the FMSF, taking into account both the United States and the Russian Federation views, as well as specific FMSF environments. Although some Russian views have been documented, very little information at the level required for formal test planning was received prior to the start of the testing campaign. Consequently, this report documents the environmental performance results of testing conducted only in the United States on TID candidates for a transparency and/or safeguards-and-security regime at the Mayak FMSF. Acceptance of these test results, any additional testing, and recommendations by those Russian Federation entities responsible for the Mayak FMSF will be required before implementing any Mayak FMSF TID program. The work documented here does not include results of a parallel vulnerability assessment of TIDs conducted at Los Alamos National Laboratory.

The TIDs tested for potential use at the Mayak FMSF include 1) the Cobra seal, fiber optic cable, and reader, 2) the 3M Confirm Tamper Tape, 3) E-Type Cup metal seal (with International Atomic Energy Agency [IAEA] scribing procedure), and 4) E-Tag Mechanical seal. In addition, four promising alternates to the $3 \mathrm{M}$ Confirm Tamper Tape were tested, based on new test and evaluation information provided by the Defense Threat Reduction Agency (DTRA). Of the previously mentioned TIDs, the ECup, the Cobra Seal, and the Confirm Tamper Tape have been extensively tested by Sandia National Laboratory and other testing entities.

The tests encompassed a representative set of environmental conditions and external influences that included temperature and humidity (normal, variable, and extreme conditions), as well as radio frequency, microwave, and magnetic fields. The radio frequency, microwave, and magnetic-field tests were only performed on devices with built-in electronics, such as the E-Tags and several of the readers. Radiation exposure testing was performed on all candidate TIDs. Finally, a variety of mechanical tests were performed to evaluate the ruggedness of each type of TID. A sample population of 70 units was used with the entire sample subjected to each test consecutively, except in the case of several of the adhesive seal tests.

All TIDs tested performed without failure during the planned ionizing radiation testing. A special radiation exposure-to-failure test for the Cobra seals showed that they are useable at more than 200 times the expected 50-year lifetime radiation dose at the Mayak FMSF. Temperature and humidity testing, appropriate to the conditions at Mayak FMSF, also resulted in no significant issues for any of the TIDs tested.

The mechanical test program resulted in significant failures of the wire loop seals, primarily because of the type of grommet used to secure the wire. Three Cobra seals also failed in this test phase. The adhesive seals performed well as a group, with minor exceptions, and should be useable wherever they

are not subjected to severe mechanical abrasion or shearing stress. Electromagnetic testing showed that 
the E-Tags were quite susceptible to failure when exposed to static discharges; however, this may or may not be an issue at the storage facility.

Based on the results of the TID tests and evaluations performed, the following conclusions are provided for each of the TID roles at the Mayak FMSF:

1) The Fissile Material Containers - The possible options for sealing the lid of the AT-400R are adhesive seals and the two wire-loop seals, the E-Type Cup Metal Seal, and the E-Tag Mechanical Seal. We recommend the E-Type Cup Metal seal with the internal scribing over adhesive seals and the E-Tag. Adhesive seals are not expected to be robust enough against container-handling hazard, and the E-Tag's associated electronic reader and software may well become obsolete during the Mayak 50-year lifecycle.

2) The Storage Nest Covers - Significant operational issues with regard to TIDs on the storage nest covers were encountered. A mockup of the nest top and cover clearly showed that none of the tested loop seals could be effectively used for this application, given the initial nest cover and mating assembly design. Pacific Northwest National Laboratory research staff proposed design-modification recommendations that could provide for the secure use of IAEA standard loop-type seals on the nest cover. However, it is our understanding that these modifications cannot be made because of significant cost and schedule impacts with respect to the entire FMSF construction. It is our judgment at this time that no IAEA or internationally accepted TID will adequately work on the storage nest cover. This puts an additional burden on the entire facility-monitoring scheme. Because there is still a Mayak Transparency Protocol requirement for a TID on the storage nest cover, we believe this issue needs to be resolved by bringing together a DTRA and multi-laboratory team to explore all possible options, such as modifications of existing technologies or combining two or more technologies, or even evaluating non-standard technologies.

3) Monitoring Equipment - Monitoring and inspection equipment, such as recording devices, video cameras, and associated data-storage media that can be stored in containers, is easily protected using the tested TID technologies. We recommend the use of Cobra seals for securing containers used to store sensitive monitoring equipment between inspections. Adhesive seals may be used during inspections for short-term applications, such as securing equipment during lunch breaks, and for the storage of less sensitive items. We recommend the $3 \mathrm{M}$ Confirm Tamper Tape for an adhesive seal due to its additional security features. The $3 \mathrm{M}$ Confirm Tamper Tape also turned out to be very resistant to abrasion and mechanical shock. 


\section{Acronym List}

ANSI

ASTM

DOE

DTRA

ESD

FMC

FMSF

F/O

IAEA

INF

MC\&A

NDA

NRC

PNNL

ROM

RF

RH

RSB

TEM

TID

U.S.

USACE
American National Standards Institute

American Society for Testing and Materials

Department of Energy

Defense Threat Reduction Agency

Electrostatic Discharge

Fissile Material Container

Fissile Material Storage Facility

Fiber Optic

International Atomic Energy Agency

Intermediate-Range Nuclear Forces

Material Control \& Accountability

Non-destructive Assay

Nuclear Regulatory Commission

Pacific Northwest National Laboratory

Read Only Memory

Russian Federation

Relative Humidity

Russian Smart Bolt

Transverse Electromagnetic

Tamper-Indicating Device

United States

United States Army Corps of Engineers 


\section{Foreword}

This Tamper-Indicating Device (TID) environmental performance testing report is submitted to the Defense Threat Reduction Agency, Cooperative Threat Reduction Division, as a technical aid in evaluating the TIDs proposed for use at the Mayak Fissile Material Storage Facility (FMSF). Several of the technologies considered, the Cobra Seal, the E-Cup, and the 3M Confirm Tamper Tape had been tested prior to this testing campaign. The tests conducted by PNNL either extended the range of previous tests, included additional tests not performed previously, or specifically addressed Mayak FMSF environments. Results of previous environmental testing of the E-Type Cup Seal are documented in SAND93-1726/1, and results of previous environmental testing of the Cobra Seal and 3M Confirm Tamper Tapes are documented in SAND93-1726/2. This report does not include results of a parallel effort in TID vulnerability assessments conducted by the Los Alamos National Laboratory.

This report was prepared by Jennifer E. Tanner, Halvor A. Undem, Bruce A. Roberts, James R. Griggs, and Sharon L. Pratt of Pacific Northwest National Laboratory. 


\section{Contents}

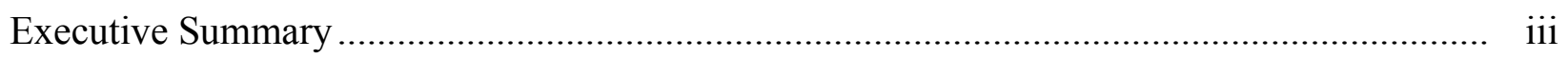

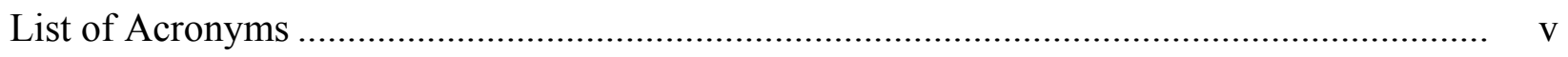

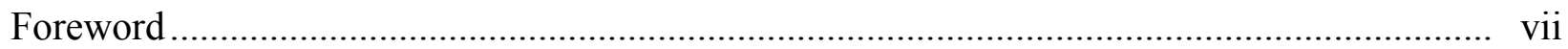

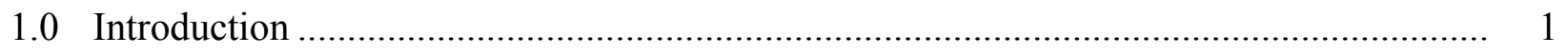

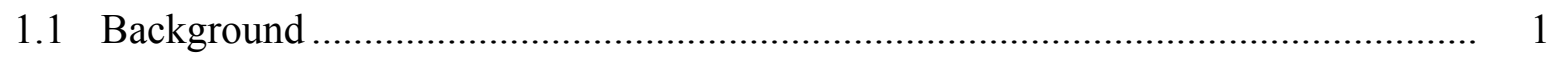

1.2 Purpose and Scope ………………………….................................................... 2

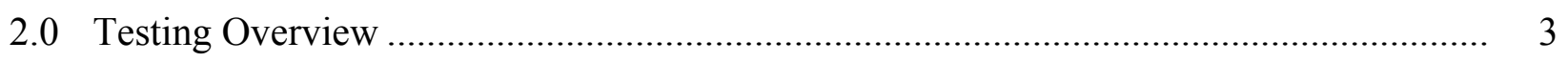

2.1 Environmental Performance Requirements ........................................................ 3

2.2 TID Technologies Tested ................................................................................ 3

2.2.1 Loop-Seal Descriptions ..................................................................... 5

2.2.2 Adhesive Seal Descriptions ........................................................................... 6

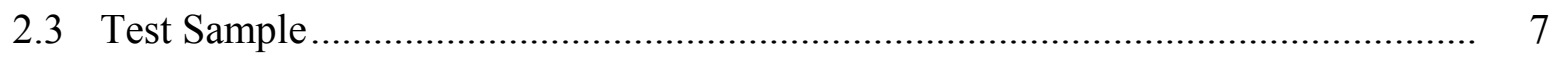

2.4 Types of Testing .............................................................................................. 7

2.5 Facilities and Locations ……………………….................................................... 8

2.6 Test and Evaluation................................................................................ 9

3.0 Operational Performance ....................................................................................... 11

3.1 Time to Install, Operator-Required Skills, and Administrative Complexity ............ 12

4.0 Test Methodology \& Results .................................................................................... 15

4.1 Ionizing Radiation Testing ................................................................................ 15

4.1.1 Gamma Exposure ............................................................................ 15

4.1.2 Neutron Exposure ................................................................................. 16

4.1.3 Cobra Seal Test to Failure .............................................................. 16

4.2 Temperature and Humidity Testing .................................................................. 18

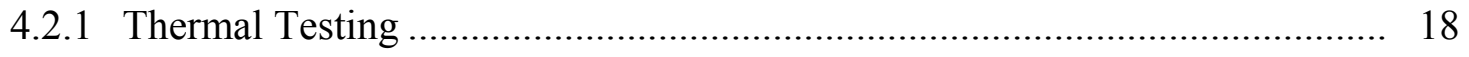

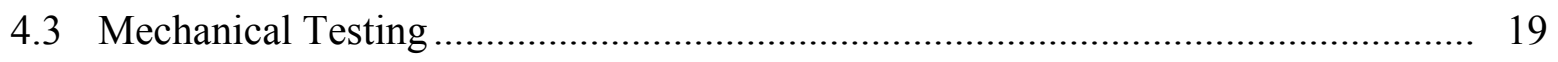

4.3.1 Pull Testing for Loop-Type Seals ……………........................................... 20

4.3.2 Drop Testing for Loop-Type Seals.............................................................. 21

4.3.3 Vibration Testing for Loop-Type Seals ………………................................ 23

4.3.4 Vibration Testing of Adhesive Seals.............................................................. 23 
4.3.5 Mechanical Shock Test ...................................................................... 24

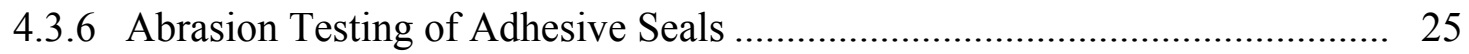

4.4 Electromagnetic Testing ................................................................................ 25

4.4.1 Sensitivity to Interfering Magnetic Fields.................................................... 25

4.4.2 Sensitivity to Interfering Microwave Fields................................................ 26

4.4.3 Sensitivity to Radiofrequency Interference .................................................... 27

4.4.4 Sensitivity to Electrostatic Discharge ………….......................................... 28

$5.0 \quad$ Summary and Recommendations ........................................................................... 31

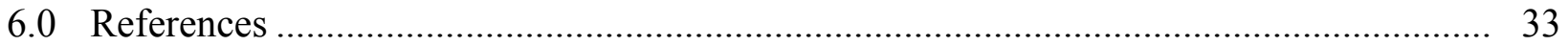

Appendix A: Environmental Test Equipment Specifications

Appendix B: CD-ROM - Pictures of Testing, Cobra Seal Images, and Laboratory Record Book

\section{Figures}

1. Loop Seal Candidates ............................................................................................ 5

2. Adhesive Seal Candidates............................................................................................. 5

3. Test and Evaluation Flowchart …………………..................................................... 10

4. Plastic/Metal Mockup of Nest Cover and Top of Nest Tube ........................................... 11

5. Recommended Nest Cover Design ............................................................................ 11

6. Bottom of a Prepared E-Type Cup Metal Seal .............................................................. 13

7. PNNL High Dose 60Co Facility ............................................................................. 16

8. Adhesive Seals and E-Cups Around the South Exposure Station ....................................... 17

9. Cobra Seals Around the South Exposure Station ......................................................... 17

10. Cobra Seal Images After 50K, 100K, 200K, 500K, 1M, and 2M Rads ............................ 18

11. Cobra Seal Body Unexposed and Exposed to 500,000 Rads ............................................. 18

12. Adhesive Seals Inside Environmental Chamber............................................................. 19

13. 10-Day Thermal and Humidity Testing..................................................................... 20

14. Loop Seal 50-lb Pull Test .................................................................................. 21

15. Cobra Seal \# 75 Before and After Pull Test .................................................................. 21

16. Loop Seal 5-lb Drop Test ..................................................................................... 22

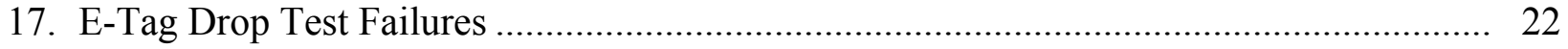




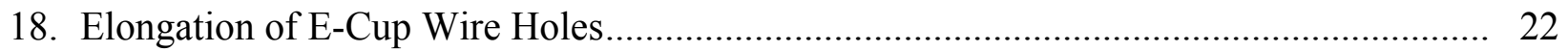

19. Single and Double-Holed Grommets.............................................................................. 23

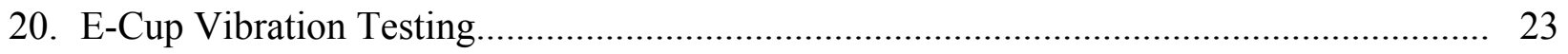

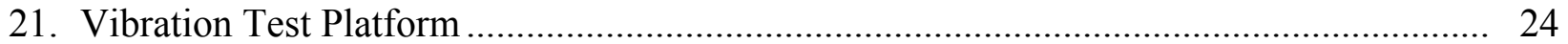

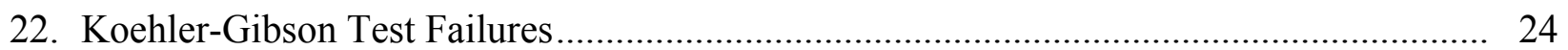

23. 113.56 L (30-Gal) Drum ready for Mechanical Shock Test............................................... 25

24. 113.56-L (30-Gal) Drum ready for Mechanical Shock Test .............................................. 26

25. Magnetic Test Chamber............................................................................................. 26

26. Microwave Test Chamber......................................................................................... 26

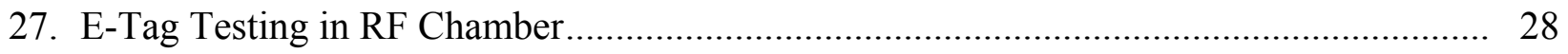

28. E-Tags During ESD Testing .............................................................................. 29

\section{Tables}

1. The Roles of TIDs in the Mayak FMSF ……...............................................................

2. General Selection Criteria for TIDs............................................................................... 3

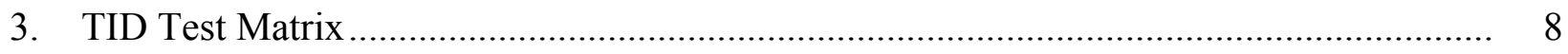

4. The Cost of Candidate TIDs ............................................................................... 12

5. Radiofrequency Test Parameters ………………..................................................... 27 


\subsection{Introduction}

Tamper Indicating Devices (TIDs) can potentially be used at the Mayak Fissile Material Storage Facility (FMSF) to enhance the protection of fissile material, surveillance and monitoring equipment, recording devices, and data-storage media. The selection of the appropriate TIDs depends on the following general criteria: security and vulnerability, reliability, functionality, safety, availability, and cost. Reliability depends on the environmental factors at the FMSF, such as radiation, temperature, humidity, and total expected exposure time (life expectancy) under these conditions. Functionality addresses issues regarding ease of operation, skill level required for operation, and the impact on facility operations. The selected technologies will be required to meet minimum performance requirements in each environment.

\subsection{Background}

U.S. and Russian technical experts have considered the issues of sealing fissile material containers, storage nest covers, and various monitoring equipment in the FMSF. A joint U.S. and Russian technical experts group exchanged information on sealing technologies and methods as developed in the United States and Russia (VNIITF, VNIIEF). Based on the results of this 1999 exchange of ideas, the following concepts (Table 1) for the roles of TIDs in the FMSF were put forward for consideration and evaluation.

Table 1. The Roles of TIDs in the Mayak FMSF

\begin{tabular}{|c|c|c||}
\hline \multicolumn{1}{|c|}{ TID Location } & U.S. Concept & Russian Concept \\
\hline FMC(a) (AT-400R) & $\begin{array}{r}\text { Russian Smart Bolt (RSB [b]), } \\
\text { E-Cup Seal }\end{array}$ & $\begin{array}{c}\text { OPP-1M, RSB } \\
\text { ZP-1, BO3 }\end{array}$ \\
\hline \multicolumn{1}{|c||}{ Storage Nest Covers } & $\begin{array}{c}\text { F/O (c) "Cobra" Seal } \\
\text { E-Cup Seal }\end{array}$ & \\
\hline $\begin{array}{c}\text { Monitoring Equipment (Recording Devices } \\
\text { Recording Device Data Storage Media } \\
\text { Video Equipment) }\end{array}$ & High Security Tamper Tape & \\
$\begin{array}{l}\text { (a) FMC = fissile material container } \\
\text { (b) RSB = Russian Smart Bolt } \\
\text { (c) F/O = fiber optic }\end{array}$ & & \\
\hline \hline
\end{tabular}

In weighing the suitability of TIDs for various applications at Mayak, one must consider them as part of an overall transparency regime and/or safeguards and security system within the full context of the monitoring scenario. This overall system may include one or more forms of continuous monitoring and other security procedures, in addition to the TIDs. The TIDs themselves are part of a system that includes the TID signature-reading system, tamper-inspection procedures and tools, installation procedures and tools, and other support equipment. Performance parameters may differ for the TID and its reader or other subsystems. The verification support system for a given TID consists of (as appropriate):

- the TID signature reader (to establish the unique identity of a controlled item) 
- any equipment, tools, and supplies required for installation and removal of a TID

- any equipment and tools required for tampering inspections (e.g., flashlight, camera).

\subsection{Purpose and Scope}

The purpose of the test and evaluation of tamper indicating devices (TIDs) described in this report is to examine existing and commercially available TID technologies for specific use at the Mayak Fissile Material Storage Facility (FMSF). In this respect, TIDs that have been used under best international safeguards practices form a natural testing baseline. TID candidacy is based on TID performance with respect to mutually agreed functional, operational, and security requirements for the FMSF, taking into account both the U.S. and the Russian Federation views, as well as anticipated environments within the FMSF. Although some Russian views have been documented, very little information at the level required for formal test planning was received prior to the start of the testing campaign. Consequently, this report currently documents the results of environmental testing of U.S. TID candidates for a transparency and/or safeguards-and-security regime at the Mayak FMSF, based largely on best international safeguards practices. Vulnerability assessments of TIDs are not within scope, but are part of a parallel effort conducted by Los Alamos National Laboratory.

General criteria for selecting TID technologies were documented at the Technical Experts Group Meeting convened at Lawrence Livermore National Laboratory April 5-10, 1999. Those technologies that appeared to meet the general criteria as suggested by both U.S. and Russian technical experts were then subjected to a U.S.-sponsored environmental test and evaluation activity, which is documented here. Consequently, the test results documented in this report provide, at least partially, the technical basis for final recommendations on TID technologies for use at the Mayak FMSF. However, this document is limited in scope to the test and evaluation of candidate TIDs under various environmental conditions and does not address the issue of additional required Russian testing, gaining approval from the Russians for the U.S. testing, or the process of certification of TIDs in Russia for use at the Mayak FMSF. 


\subsection{Testing Overview}

\subsection{Environmental Performance Requirements}

The first step in test planning is to establish requirements for TIDs based on expected environments and use within a specified security and facility-monitoring concept. At present, many of these formal performance standards have not been established for TIDs to be used under the Mayak Transparency regime. In lieu of these formal requirements, the TID test and evaluation program followed general guidance established in the Protocol of the Meeting of the Technical Experts Group on Technical Issues Related to Transparency Measures of Material to be Stored at the Fissile Material Storage Facility of the Mayak Production Association, April 10, 1999 (Table 2). Numerical test specifications were derived from MIL-STD-810E, Environmental Test Methods and Engineering Guidelines, IEC 60068, Environmental Testing, and IAEA STR-284, Qualification Test Specification for Non-destructive Assay $(N D A)$ and Containment \& Surveillance (C\&S) Equipment. Additional environmental-specification information was incorporated from the working document provided by the U.S. Army Corps of Engineers, Parameters and Assumptions for the Thermal Analyses of the Russian Fissile Materials Storage Facility Enhanced Plutonium Loading, Volume 7, January 20, 1999. This set of standards best encompasses specific Mayak FMSF guidance with respect to TIDs, best U.S. domestic safeguards practices, and best international safeguards practices.

Table 2. General Selection Criteria for TIDs

\begin{tabular}{|l|l|}
\hline \multicolumn{1}{|c|}{ US } & \multicolumn{1}{|c|}{ RF } \\
\hline 1. Vulnerability/Security & $\begin{array}{l}\text { Is it in accordance with the laws of the Russian } \\
\text { Federation }\end{array}$ \\
\hline 2. Reliability in FMSF Environment & $\begin{array}{l}\text { Possibility of procurement and supply from a Russian } \\
\text { producer and manufacturer }\end{array}$ \\
\hline 3. Impact to Facility Operations & $\begin{array}{l}\text { Presence of a unique identifying attribute and how } \\
\text { resistant it is to falsification }\end{array}$ \\
\hline 4. Impact to Facility Design and Construction & Reliability requirements, life expectancy \\
\hline 5. Safety & The ability to withstand the impact of outside factors \\
\hline 6. Availability for Testing and Procurement & Cost \\
\hline 7. Cost of TIDs and Equipment & Ease of use, simplicity, time to apply and verify \\
\hline & Possibility to have automated control features \\
\hline & Compatibility with FMSF automated MC\&A system \\
\hline & Personnel Safety \\
\hline
\end{tabular}

\subsection{TID Technologies Tested}

The choice of TIDs tested was driven by two additional factors, including the general ones already stated. The primary factor was to exploit best international practices and provide updated test and evaluation results for those TIDs that have found broad international acceptance within the international safeguards and security community. If these are acceptable in the Mayak environments, they should also 
be readily available in most commercial markets. The second factor was to examine alternative TIDs that have recently undergone test and evaluation as documented by the Defense Threat Reduction Agency (DTRA) Arms Control Technology Division (OST) (TRW 2000). Hence, we have expanded the number of the adhesive TID candidates beyond that of common international standards.

The TIDs tested for use at the Mayak FMSF were as follows: 1) the Cobra seal, fiber optic cable, and reader, 2) a set of five adhesive seals, including (2a) the 3M Confirm Tamper Tape; (2b) the 3M TED adhesive seal; (2c) the Koehler-Gibson adhesive seal, (2d) the MIKOH SubscribeTM adhesive seal, and (2e) the 3M/Alcan adhesive seal, 3) E-T ype Cup metal seal (with International Atomic Energy Agency [IAEA] scribing procedure), and 4) E-Tag Mechanical seal. These TIDs are pictured in Figures 1 and 2 and are also described elsewhere in this section. Of the previously mentioned TIDs, the E-Cup, the Cobra Seal, and Confirm Tamper Tape have also been extensively tested by Sandia National Laboratory (SNL 1993 and 1995) and other testing entities, including the Joint Research Centre in Ispra, Italy (Korn and Gartner 1996).

As just mentioned, the four alternate candidates to the 3M Confirm Tamper Tape were also included in the testing in light of recent TID test results obtained by DTRA/OST. The 3M company has come out with another adhesive seal called the TED, and a German company, Koehler-Gibson, produces a duragraphic etched aluminum adhesive seal. Both appear to perform well under harsh environmental conditions. The other two adhesive seals are MIKOH's SubScribe and the 3M/Alcan. Some of the other TIDs that were tested by DTRA/OST, such as the mechanical Relcor seal, are not physically compatible with the AT-400R storage containers or storage nest covers or were active systems and therefore not included in the testing.

These tests required a significant number of samples of TIDs, as well as their support equipment (e.g., signature readers). A number of samples of the adhesive seals were supplied without cost from the vendors. Other seals were purchased, such as the E-Tag Mechanical Seals and readers from Aquila and the E-Type Cup metal seals from American Manufacturing \& Casting prior to the start of testing. The Cobra Seal System was already available in the laboratory, but additional seal bodies were purchased to make up the sample population. The TID samples that survived the full test sequence have been saved and are available for historical purposes.

The complete list of the candidate TID technologies that were tested is presented below and described in the following subsections. All of these are currently commercially available in the United States, and many of them are also available internationally. As already stated, samples of Russian TIDs were not available to include in the testing.

Adhesive Seals Loop Seals

3M Confirm E-Type Cup (copper-brass version)

3M TED E-Tag

Alcan/OTF* Cobra

MIKOH SubScribe

Koehler-Gibson

*Formerly 3M/Alcan 


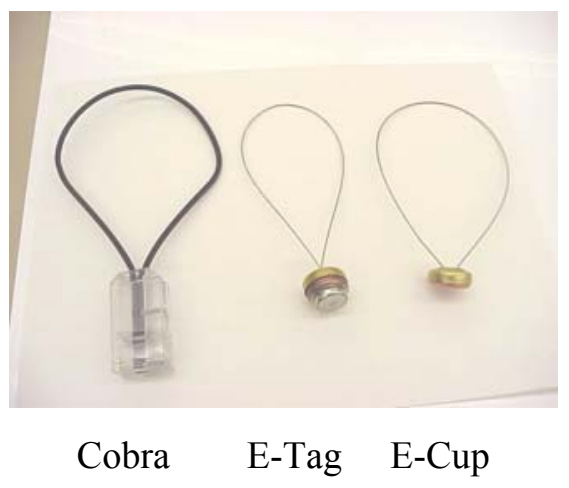

Figure 1. Loop Seal Candidates

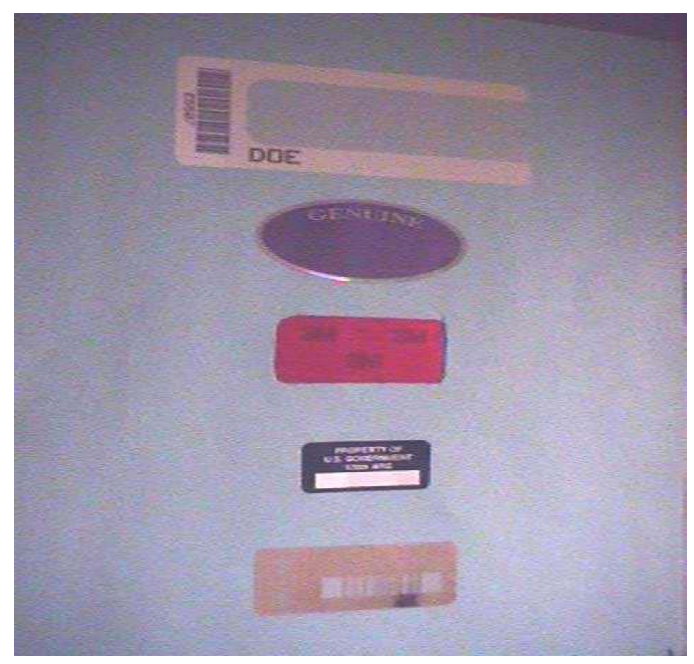

3-M Confirm, ALCAN OTF, 3M TED, Koehler-Gibson, MIKOH SubScribe

Figure 2. Adhesive Seal Candidates

\subsubsection{Loop-Seal Descriptions}

\section{Cobra Seal and Imaging System}

The Cobra Seal is a passive, fiber-optic loop seal consisting of a clear, polycarbonate seal body and loop of fiber-optic cable. The one-piece polycarbonate seal body has two clamping pins that secure the cable in the seal body and one specially designed cutting blade that cuts the fiber-optic cable in a random fashion. The fiber-optic cable has 64 plastic fibers within a black polyethylene jacket. When the seal is installed and the fibers are cut, a unique pattern is created on the seal face. This unique pattern is associated with an alphanumeric identifier and is recorded either photographically or digitally and stored for future reference and verification. The standard Cobra Seal Imaging system consists of a QV-30 digital camera and Casio DP-8000 printer coupled with proprietary optics, illumination and alignment accessories, and a portable power pack.

\section{E-Type Cup Metal Seal}

The E-Type Cup and wire metal seal is used as a TID in many domestic safeguards and routine shipping applications. It consists of a multi-strand wire, a grommet, and two halves of a metal cup that press-fit together. One of the halves of the E-Cup has two holes through which the ends of the wire are threaded. The wire is then threaded through the grommet, the grommet and wires are crimped, and the ends of the wires trimmed so that the grommet holding the ends of the wire will fit within the closed cup. The two halves of the E-Cup are then snapped together, and the seal is made.

\section{E-Tag Mechanical Seal}

The E-Tag Mechanical Seal, manufactured by Aquila, is a standard metal (copper-brass) E-Type Cup seal with an inexpensive, small E-Tag (iButton touch memory manufactured by Dallas Semiconductor) 
implanted in the case. The E-Tag contains a unique electronic serial number that is written in ROM at the time of manufacture. The seal is easily validated with a hand-held device without the need to remove the seal from the container.

\subsubsection{Adhesive Seal Descriptions}

\section{M Confirm Tamper Tape and TED}

The 3M Confirm Tamper Tape is an adhesive-backed label possessing various tamper-indicating, transfer-resistant, and counterfeit-resistant properties. It consists of multiple layers of polymers, patterns, devices, and other materials mixed with layers of adhesives. Designs or logos are incorporated into the tape using material based on coated glass beads embedded in a brittle bonding layer, which, in the event of tampering, is easily disrupted and distorted. Printed serial numbers and accompanying bar codes printed on each label help provide a unique identifier and are printed in such a way that tampering with the numbers will inevitably disrupt the pattern or logo.

The 3M TED is an adhesive label consisting of laminated polymer film layers with colored indicators applied to opposing surfaces between layers. When the label is initially installed, one set of indicators is visible. When the label is removed, another set of indicators becomes visible, making the removal or tampering readily apparent. The tamper indication is irreversible so that removal and reapplication without detection is very difficult.

\section{Koehler-Gibson Tag}

The Koehler-Gibson tag is composed of duragraphic etched aluminum. This material consists of an aluminum substrate coated by an anodized layer that has been etched away to create a graphic image. Any graphic image can be transferred to the anodized aluminum. The substrate material is 1100 series aluminum, and a $3 \mathrm{M}$ adhesive backing is used for adhesive seals. The duragraph material is ideal for conditions requiring exposure to sunlight, excessive heat, and resistance to abrasives and chemicals.

\section{MIKOH SubScribe Adhesive Seal}

The SubScribe adhesive seal employs a subsurface laser marking technology for variable marking of internal layers of laminated, metalized polyester/polypropylene. Removal of the seal by peeling causes delamination and reveals a previously hidden honeycomb pattern. The adhesive seals can be printed with graphics and text, including bar codes and serial numbers, for identification.

\section{Alcan/OTF Optical Thin Film Authenticating Device (formerly offered by 3M)}

The Alcan/OTF adhesive seal is a polyester/aluminum laminate label. Peeling, puncturing, or slitting the label reveals a covert image in a subsurface layer by changing color. The covert image can be a logo, text, or both, tailored to the user's needs. It is available in a variety of colors. Surface graphics can be applied with a variety of standard print methods and can include bar codes and serial numbers. 


\subsection{Test Sample}

Test samples consisting of 70 units were analyzed for determining whether a candidate TID technology would perform adequately when used at the Mayak FMSF. Based on the expectation that all candidate TIDs would pass the tests outlined in this section, a maximum failure rate was determined for the given test sample size and a given confidence level. Assuming that all 70 TIDs passed all tests, a failure rate of less than $3.2 \%$, with $90 \%$ confidence, would be established. Note that given successful results in testing the $70 \mathrm{TIDs}$, the $3.2 \%$ failure rate would be an upper bound for the true failure rate. This true failure rate may well be considerably less than $3.2 \%$. If demonstrating a maximum failure rate of less than $1 \%$ at a $90 \%$ confidence level had been the desired goal instead, a test sample of 230 TIDs would have been necessary, again with no failures observed during testing. This number being prohibitive, it was decided that 70 units was a much more practical number to work with and test.

\subsection{Types of Testing}

Environmental performance testing and evaluation of the TIDs slated for use at the Mayak Fissile Material Storage Facility is essential in determining whether they will withstand the hostile and specific environments to which they will be exposed. The Cobra Seal and E-Cup have been tested by Sandia National Laboratory (SNL 1993 and 1995), and the Confirm Tamper Tapes have been tested extensively by Pacific Northwest National Laboratory (Wright et al. 1995a; Wright et al. 1995b) and the Joint Research Centre T.E.M.P.E.S.T. Laboratory (Azzalin et al. 1996). The remaining adhesive seals have been tested by DTRA/OST for functionality, ruggedness, and durability with a focus on outdoor applications. All candidate TIDs were also subjected to thermal, mechanical, non-ionizing radiation, and ionizing radiation environments as appropriate for the Mayak FMSF.

The tests encompassed a representative set of environmental conditions and external influences that included temperature and humidity (normal, variable and extreme conditions), radiation (neutron and gamma), as well as radio frequency, microwave, and magnetic fields. The radio frequency, microwave, and magnetic field tests were only performed on devices with built-in electronics, such as the E-Tag Mechanical seal and TID readers, if applicable. Finally, a variety of shock, pull, and vibration tests were performed to evaluate the ruggedness of each type of TID. The cumulative effect of the above mentioned tests is believed to represent a reasonable worst case for the wear and tear that the TIDs will experience throughout their lifetime, from the time they are applied, through transport and handling, and for the environment in which they will be permanently stored. The tests closely followed applicable guidelines found in MIL-STD 810 (Military Test Standard 1995) and IEC 60068 (IEC 1988; IEC 1990) (hereafter referred to as IEC 68). These guidelines meet or exceed the guidelines set in IAEA STR-284 (Demetriuou et al. 1993) and applicable American National Standards Institute (ANSI) or American Society for Testing and Materials (ASTM) standards. A subset of the IEC 68 tests is contained in IAEA Test Procedure V.1.2 (Korn and Gartner 1996). The types of TIDs and the tests performed are found in Table 3. Specific test parameters are detailed in Section 4. These test sequences and parameters equal or exceed best international practices for TIDs in safeguards and security scenarios. 
Table 3. TID Test Matrix

\begin{tabular}{|c|c|c|c|c|c|c|}
\hline \multirow[b]{3}{*}{ Ionizing Radiation $(\mathrm{n}+$ ) } & \multicolumn{2}{|c|}{ Cobra } & \multirow[t]{2}{*}{ Adhesive Seals } & \multicolumn{3}{|c|}{$\begin{array}{c}\text { E-Type } \\
\text { Cup (IAEA) }\end{array}$} \\
\hline & \multicolumn{2}{|c|}{ Seal Reader } & & \multirow{2}{*}{\begin{tabular}{|c|} 
Seal \\
$\mathrm{Y}$
\end{tabular}} & \multicolumn{2}{|c|}{ Seal|Reader } \\
\hline & $\mathrm{Y}$ & $\mathrm{N}$ & $\mathrm{Y}$ & & $\mathrm{Y}$ & $\mathrm{N}$ \\
\hline \multicolumn{7}{|l|}{ Temperature and Humidity } \\
\hline Cold Temperature & $\mathrm{Y}$ & $\mathrm{N}$ & $\mathrm{Y}$ & $\mathrm{Y}$ & $\mathrm{Y}$ & $\mathrm{N}$ \\
\hline Dry Heat & $\mathrm{Y}$ & $\mathrm{N}$ & $\mathrm{Y}$ & $\mathrm{Y}$ & $\mathrm{Y}$ & $\mathrm{N}$ \\
\hline Thermal and Humidity & $\mathrm{Y}$ & $\mathrm{N}$ & $\mathrm{Y}$ & $\mathrm{Y}$ & $\mathrm{Y}$ & $\mathrm{N}$ \\
\hline \multicolumn{7}{|l|}{ Mechanical } \\
\hline Abrasion & $\mathrm{N}$ & $\mathrm{N}$ & $\mathrm{Y}$ & $\mathrm{N}$ & $\mathrm{N}$ & $\mathrm{N}$ \\
\hline Shock & $\mathrm{N}$ & $\mathrm{N}$ & $\mathrm{Y}$ & $\mathrm{N}$ & $\mathrm{N}$ & $\mathrm{N}$ \\
\hline Drop* & $\mathrm{Y}$ & $\mathrm{N}$ & $\mathrm{N}$ & $\mathrm{Y}$ & $\mathrm{Y}$ & $\mathrm{N}$ \\
\hline PullP Pull* & Y & $\mathrm{N}$ & $\mathrm{N}$ & $\mathrm{Y}$ & Y & $\mathrm{N}$ \\
\hline Vibration & $\mathrm{Y}$ & $\mathrm{N}$ & $\mathrm{Y}$ & $\mathrm{Y}$ & $\mathrm{Y}$ & $\mathrm{N}$ \\
\hline \multicolumn{7}{|l|}{ Electro-Magnetic } \\
\hline Radio Frequency & $\mathrm{N}$ & $\mathrm{N}$ & $\mathrm{N}$ & $\mathrm{N}$ & $\mathrm{Y}$ & $\mathrm{Y}$ \\
\hline Magnetic Field & $\mathrm{N}$ & $\mathrm{N}$ & $\mathrm{N}$ & $\mathrm{N}$ & $\mathrm{Y}$ & $\mathrm{Y}$ \\
\hline Microwaves & $\mathrm{N}$ & $\mathrm{N}$ & $\mathrm{N}$ & $\mathrm{N}$ & $\mathrm{Y}$ & $\mathrm{Y}$ \\
\hline Electrostatic Discharge & $\mathrm{N}$ & $\mathrm{N}$ & $\mathrm{N}$ & $\mathrm{N}$ & $\mathrm{Y}$ & $\mathrm{Y}$ \\
\hline
\end{tabular}

Following each round of testing, the TIDs were inspected and a "pass" or "fail" determination made. Failure modes were those that would be observable by an inspector or detected as part of the verification process. A TID either passed or failed at the end of each round of testing. There was no quantification of the degree of failure. In the case of the E-Type Cup seal that can only be verified through destructive analysis, the seals were not authenticated until completion of all testing. Prior to the final test and destructive evaluations, E-Type Cup seals were only inspected for failure by checking the condition of the wire loop and pulling on the seal, as a TID inspector would do in normal practice.

\subsection{Facilities and Locations}

Environmental performance tests and associated analyses were conducted at PNNL's Radiological Standards and Calibration Laboratory in Richland, Washington. An ANSI Testing Laboratory and various radiation-exposure facilities are all part of the Laboratory. These facilities have extensive experience from over 10 years of support to the U.S. Department of Energy (DOE) and the U.S. Nuclear Regulatory Commission (NRC) in developing and conducting environmental and performance testing of a wide variety of instrumentation and equipment in various scenarios. Available test equipment encompasses a complete set of environmental variables. Test variables include temperature and humidity (normal and extreme ranges), rainfall, pressure (low and high), radio frequency fields, and magnetic fields. Specialized tests on light sensitivity, radiation sensitivity, and special atmospheres can also be performed. In addition, specialized tests for evaluating items for susceptibility to power-line disturbances (surges, sags, and transients) are also available. Finally, a variety of shock and vibration and crushing 
equipment is available to analyze for ruggedness and rough handling. Testing at this facility has been conducted following both military and industrial performance standards and as such was able to provide an appropriate array of environments and testing parameters to qualify TIDs for use at the Mayak storage facility. Equipment specifications of individual test apparatus used in this testing program are given in Appendix A.

\subsection{Test and Evaluation}

The flowchart in Figure 3 shows the steps that each seal or group of seals followed through the testing and evaluation process. All seals underwent ionizing radiation, temperature and humidity, mechanical, and electromagnetic testing, in that order. For some types of equipment, some of the test steps were not performed (e.g., seals that have no electronic elements did not need electromagnetic testing). Sealverification equipment was only tested where conditions might cause temporary failure but not permanent damage, such as putting an electronic device in a magnetic field. Laptop computers and the Cobra Seal Camera were not subjected to any of the tests due to the high risk of permanent damage. 


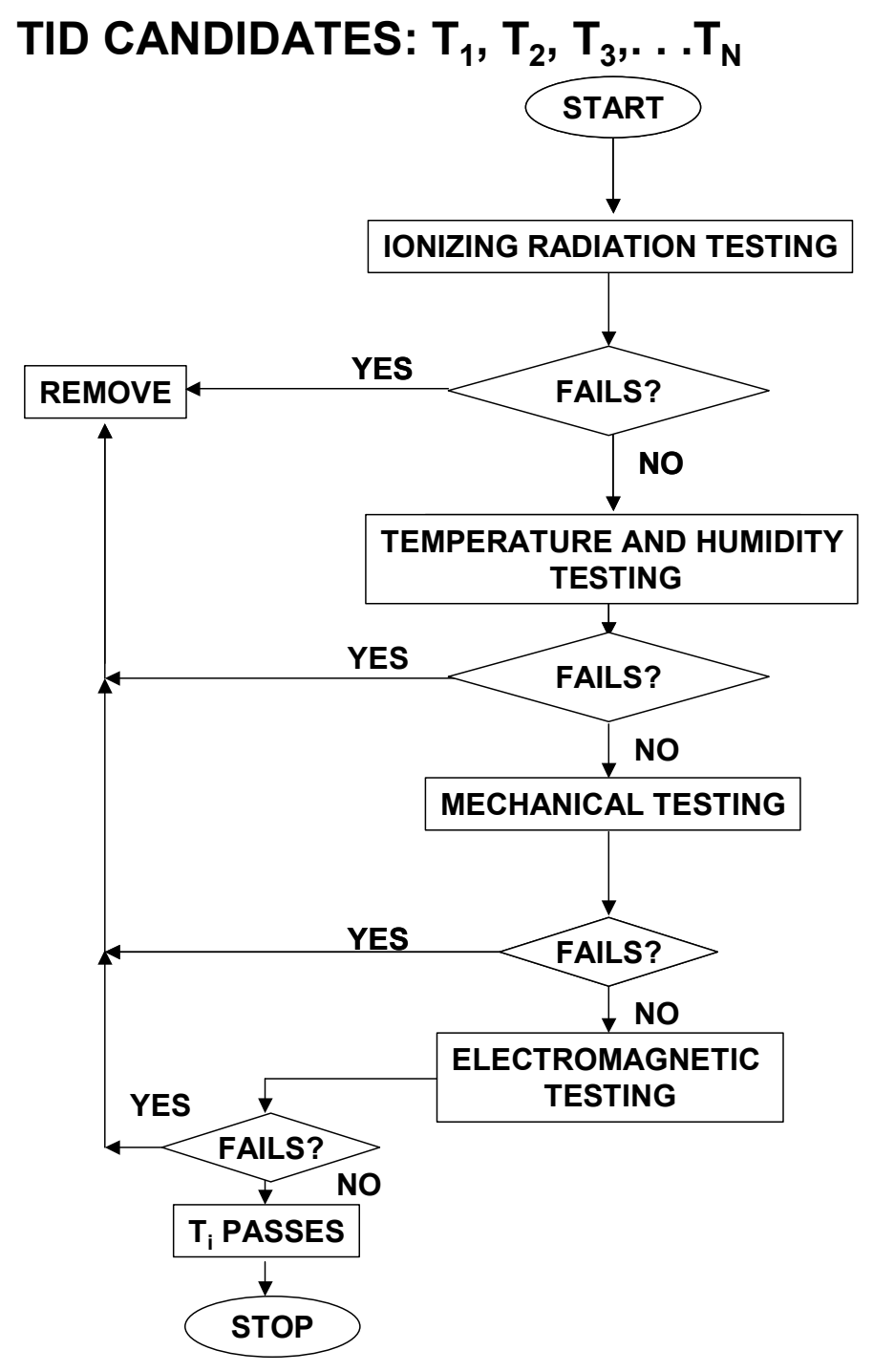

Figure 3. Test and Evaluation Flowchart 


\subsection{Operational Performance}

The TIDs tested as part of this project were thought to be compatible with the containers or items anticipated for application at the Mayak FMSF. To facilitate operational comparison of the seals and to provide demonstrations, a full-scale plastic mockup of the nest cover and top of the nest tube was constructed, utilizing drawings provided by the United States Army Corps of Engineers (USACE). The mockup, shown in Figure 4, proved very useful in demonstrating some serious shortcomings in the planned design with respect to the use of TIDs. A problem was found in the design that would not allow the nest cover to be effectively sealed with a loop-type TID. An E-Tag or E-Cup seal would fit in the recessed hole in the nest cover; however, it is quite possible that the lid could be lifted and returned to place without actually disturbing the seal. The Cobra loop seal would not fit in the existing design because the fiber-optic cable is too large, and the seal itself would protrude above the nest-cover surface. This problem could be corrected by a PNNL-recommended design change to the nest covers. The change calls for two additional holes to be drilled in the cover and a small hollow box welded to the outside of the top of the nest tube. A graphical representation of the proposed design concept is shown in Figure 5. These recommended changes would allow effective use of any approved loop-type seal.

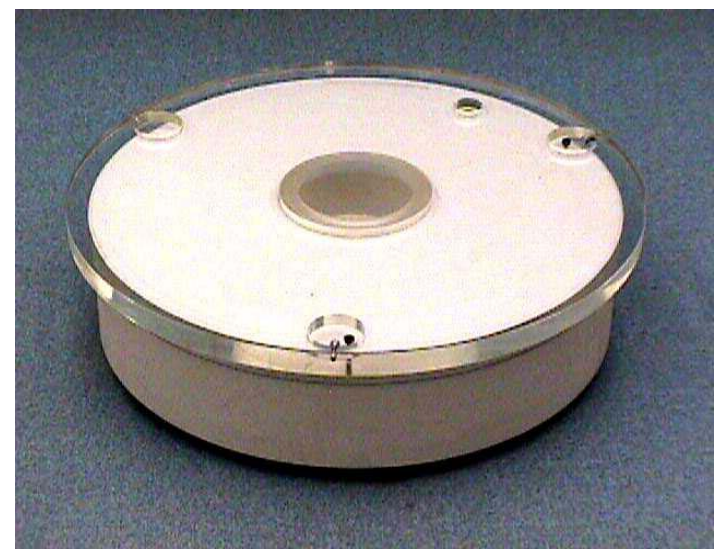

Figure 4. Plastic/Metal Mockup of Nest Cover and Top of Nest Tube

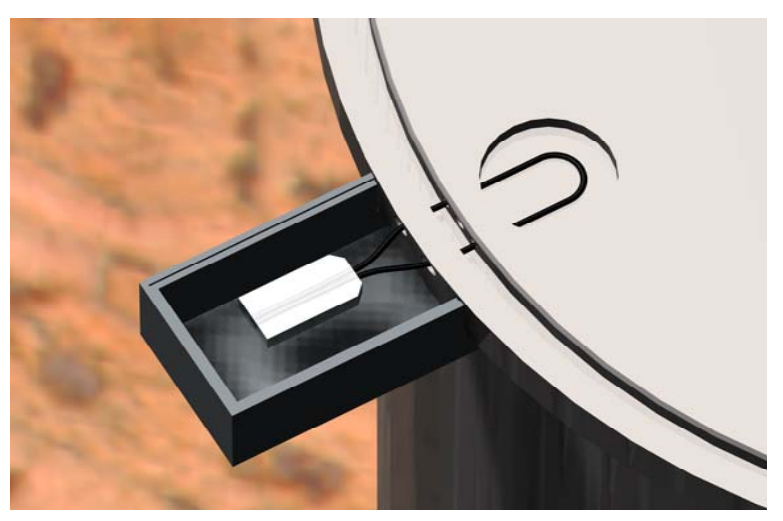

Figure 5. Recommended Nest Cover Design

Factors to consider in operational performance:

- Availability

- Cost

- Time and skill level required to install and inspect.

All TIDs tested in this program were commercially available. There were no samples of Russian Federation TIDs available upon initiation of this test program. The costs associated with each TID technology at the time of this test program are shown in Table 4. 


\subsection{Time to Install, Operator-Required Skills, and Administrative Complexity}

\section{Pressure-Sensitive Adhesive Seals}

Clearly, the pressure-sensitive adhesive seals were fastest and easiest to install, requiring only a short training and practice session. Extreme care and consistency must be taken to properly prepare the surface of the object for applying adhesive seals. This may entail sanding, scraping, and cleaning. In this regard, the most difficult task encountered was complete removal of previously applied adhesive seals. After any of the adhesive seals are applied, prudent inspection requires a close look to record any serial numbers or to detect any signs of tampering.

Table 4. The Cost of Candidate TIDs

\begin{tabular}{|l|l|}
\hline TID & Cost \\
\hline Cobra Seal (polycarbonate body) & $\$ 32$ each \\
Cobra Seal system w/camera plus printer & $\$ 10,000$ \\
\hline E-Tag Mechanical Seal & $\$ 10$ each \\
Electronic Reader & $\$ 90$ \\
\hline E-Type Metal Cup Seal & $\$ 1$ each \\
\hline 3M Confirm Tamper Tape & $\$ 0.44$ each (total quantity 10,000) \\
\hline MIKOH SubScribe & $\$ 0.05-\$ 0.25$ each \\
\hline Koehler-Gibson & $\$ 0.67-\$ 0.97$ each \\
\hline
\end{tabular}

For this test campaign, 70 stainless steel plates, 12.7 x $25.4 \mathrm{~cm}$ (5 in. x $10 \mathrm{in}$.), were prepared on which to place a set of each of the five different seals. The metal plates were cleaned with glass cleaner and then washed several times with ethanol to remove the machine oil prior to the application of the seals. Once prepared, each set of adhesive seals was added to a metal plate. The $3 \mathrm{M}$ Confirm at the top was followed by the ALCAN (now called OTF), 3M TED, Koehler-Gibson, and finally, the MIKOH Subscribe ${ }^{\mathrm{TM}}$ Seal. For the shock-test portion of this report (Section 4.3), a small sample of six of each type of adhesive seal was applied to the rim of a 113.56-L (30-gal) drum.

\section{E-Type Cup Metal Seal}

Preparation of the E-Cups is a multi-step process, requiring care and consistency. The E-Cups were prepared by taking approximately $30.5 \mathrm{~cm}$ (12 in.) of 49-strand stainless steel cable, inserting each cut end through one of the two holes in the top half of the E-Cup, and then threading the ends in opposite directions through either the single-holed metal sleeve/grommet or the double-holed metal sleeve/grommet. A crimping tool was used to crimp the metal grommet in such a way that the two ends of the wire were held firmly in place within the grommet. The bottom half of the E-Cup was prepared by heating it on a hotplate until a solder wire would melt when touched to the bottom of the cup on the 
inside. The melted dots of solder created a random design on the bottom of each E-Cup. After removing the E-Cup from the hotplate, a scribing tool was used to scratch a random design in the melted solder to give a unique identifying pattern to each individual seal. An example of the bottom of a prepared E-Cup is shown in Figure 6. The bottom of each seal containing the design was then photographed to give a record of the seal for verification purposes. After this was accomplished, the tops (which had been prepared previously with the wire and grommet/sleeve) and the bottoms containing the solder design were snapped together to produce the tamper-indicating seal. Under normal procedures, of course, these seals are only snapped together when the container is actually sealed.

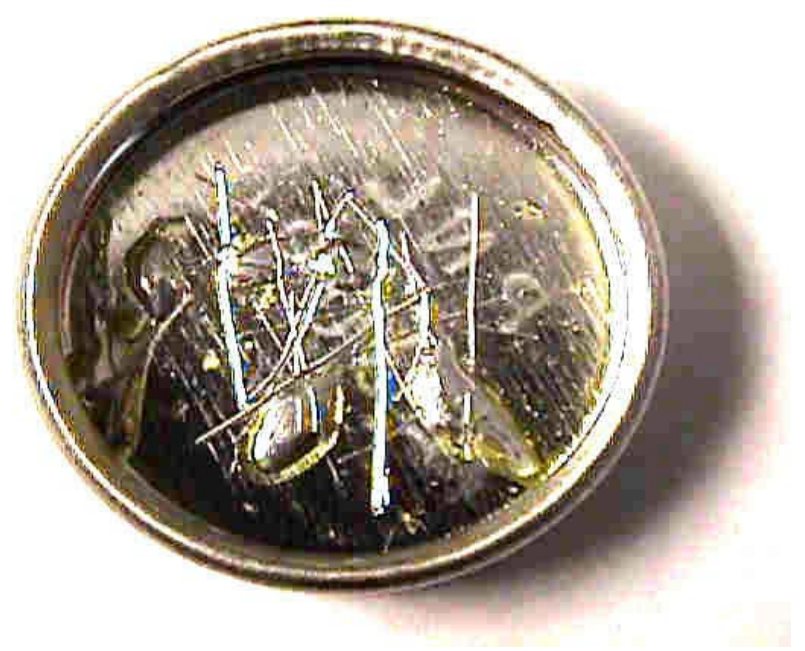

Figure 6. Bottom of a Prepared E-Type Cup Metal Seal

Interim inspection of the seals can be accomplished by reading the (very small) number on the base of the seal, closely inspecting the length of the wire, and pulling on the seal to ensure that the wires remain connected. Only after the seal is broken can a final verification of seal authenticity be determined. This process requires carefully cutting the seal around the perimeter so that the base is not disturbed, rephotographing the seal, and visually comparing the before and after results. Given a large number of seals, this is a complex administrative and time-consuming process.

\section{E-Tag Mechanical Seal}

E-Tag preparation was somewhat simpler than the E-Cups. The soldering, scratching, and photography steps were not performed, but could have been done as an option. The bottom of each seal in the E-Tag includes a small chip, which, when touched with the electronic reader, reads out the number etched on the bottom of the seal. The E-Tag numbers were read visually and compared with the readings from the manufacturer-supplied electronic reader, wires were applied, grommets were crimped, and seals were pressed together. During each stage of the test process, the seals were visually inspected for integrity, and the serial numbers were read electronically. Because the E-Tags were not initially soldered and scratched for this test series, the final procedure of cutting them open and comparing photographs was not necessary. 


\section{Cobra Seals}

The Cobra Seals were assembled as per the instructions of the manufacturer. A length (approximately $45.7 \mathrm{~cm}$ [18 in.]) of plastic Fiber Optic cable was cut with scissors for each Cobra seal to be assembled. The two ends of the cable were threaded through the Cobra seal, and the seal was placed in the Monotool. In most cases at this point, the Monotool was screwed down to secure the cable inside the seal body and to sever some of the fibers within the cable. This action creates a unique pattern of light when light is transmitted through the cable. In the Cobra Seal, the light is generated from a device attached to the Cobra Seal Reader, which emits light as a picture is taken of the two ends of the cable encased in the seal. The Monotool is designed to perform two functions. First, it is supposed to firmly crimp the two ends of the fiber optic cable together, severing several of the fibers, and second, it makes a clean cut of the fibers at the reading end of the seal so that the seal will fit snuggly and uniformly into the reader. The Monotool is not a robust instrument, and after having prepared about half of the sample seals, the tool failed mechanically. Test-sample preparations were completed by hammering the guillotine portion of the seal down with a flat-blade screwdriver to partially sever the fibers and cut off the fiber-optic cable at the end of the seal.

All of the Cobra Seals were photographed and the images saved for comparison and verification. During each phase of the testing process, the cobra seals were re-imaged and stored, creating a significant database of photos. This database is stored on a CD and provided as a supplement to this document. There can be persistent and recurring inconveniences in developing this database. For example, we discovered that the camera could only record and store 63 images, so recording the images of all 70 seals required downloading some of the images to a computer midway through the process. If the digital camera had a removable disk (a feature of newer digital cameras), it would have speeded the process considerably. Comparison of the seal images is a tedious manual process, but is the only effective way to verify the authenticity of the seal. For example, during the pull testing of the cobra seals, three of the seals failed by having the fiber-optic cable withdraw very slightly. This was not detected until an inspection of the images revealed a blurred cable image. It is noted in Section 4 of this report that the three cobra seals that failed had all been prepared after the Monotool failure. 


\subsection{Test Methodology \& Results}

The safe and secure storage of weapons-origin material in the Mayak FMSF is in part dependent on the ruggedness and durability of the technologies implemented under the Mayak Transparency Protocol. In particular, TIDs and in situ monitoring equipment may be required to operate without failure for a maximum of 50 years. Thus, the radiation, temperature, and humidity conditions within the nests and within the storage massif must be documented and taken into consideration when selecting and testing candidate technologies.

The primary conditions that will affect the operation of electronic equipment used for physical security and safeguarding fissile material are the temperatures and the radiation fields present. Elevated temperatures will shorten the lifetime of most electronics. The combination of elevated temperatures in a radiation field will adversely affect both materials and electronics.

\subsection{Ionizing Radiation Testing}

Most of the equipment at the FMSF will be exposed to significant gamma and neutron radiation fields over the lifetime of the facility. The TIDs located on the lids of the AT-400R containers will be at greatest risk of radiation damage. This necessitated the testing of all the TIDs by exposing them to realistic neutron- and gamma-radiation fields. Exposure facilities were available with gamma fields of up to $70,000 \mathrm{R} /$ hour ${ }^{60} \mathrm{Co}$ and $300 \mathrm{R} /$ hour ${ }^{137} \mathrm{Cs}$. There were also various neutron sources available, including a ${ }^{252} \mathrm{Cf}$ source traceable to the National Institute of Standards and Technology with a flux of about $10^{7} \mathrm{n} / \mathrm{cm}^{2}$-s. Previous radiation testing had exposed TIDs to $1000 \mathrm{R}$ gamma radiation (SNL 1993; SNL 1995). However, for the Mayak FMSF, the tests increased the maximum exposure to 2000-R gamma radiation and approximately 130-rem neutron radiation, based on calculations of the expected radiation fields in the storage nests. The radiation field in the storage nest is a worst-case scenario; the radiation field drops off significantly on top of the storage nest cover.

\subsubsection{Gamma Exposure}

Gamma irradiations were performed at the PNNL High Dose ${ }^{60}$ Co Facility in the 331 Building. The gamma exposure rate is variable, depending on the number and proximity of ${ }^{60} \mathrm{Co}$ source tubes used and the location of the items during irradiation. The ${ }^{60} \mathrm{Co}$ source tubes and irradiation platform are shown in Figure 7. Due to space limitations on the irradiation platform, the gamma exposure was performed in two stages. During the first stage, 52 plates with adhesive seals were irradiated, and during the second stage, the remaining 18 plates and all the loop seals (Cobra, E-Cups, and E-Tags) were irradiated. The exposures lasted about 21 hours each and were completed during the last week in July. 


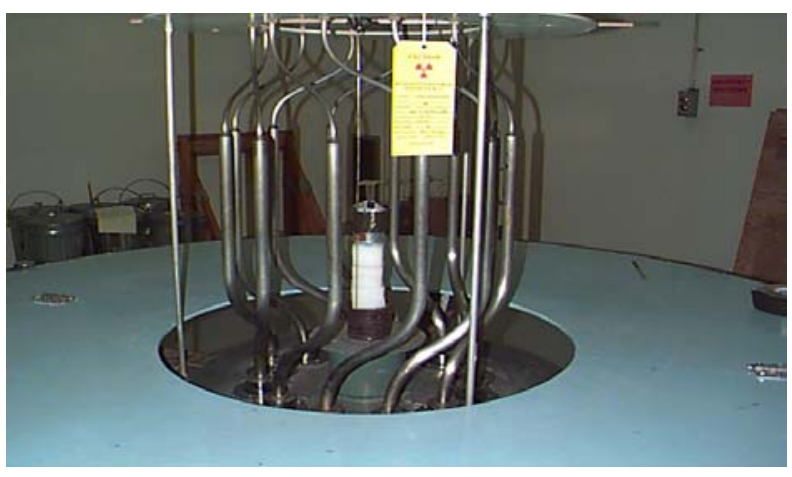

Figure 7. PNNL High Dose ${ }^{60}$ Co Facility

There were no failures following the gamma exposure test. The adhesive seals showed no observable degradation, the E-Type Metal Cups did not fail when pulled, and the E-Tags were read out successfully. The Cobra Seals were visually inspected for material defects, and the fiber-optic images were recorded and saved for future analyses.

\subsubsection{Neutron Exposure}

All candidate TIDs were exposed to 130 -rem neutron radiation from bare ${ }^{252} \mathrm{Cf}$ in the Low Scatter Room of the 318 building. The south station in the Low Scatter Room was used since it had a Plexiglas ring holder for exposures at a 50-cm-radius reference distance. This Plexiglas ring allowed the stainless steel plates to be easily set up in a reproducible manner on the irradiation platform. However, only 24 plates could fit around the ring at one time; therefore, the irradiations had to be performed four times. The first and second irradiations exposed 24 stainless steel plates, the third irradiation exposed the remaining 22 plates, the E-Tags, and the E-Type Metal Cup seals (Figure 8), and the fourth irradiation exposed the sample population of Cobra Seals (Figure 9). Due to the neutron source strength at the time of testing, the exposures took about 42 hours at the reference distance of $50 \mathrm{~cm}$. The neutron exposures were started during the first week of August and completed August 20, 2000.

There were no TID failures following the neutron exposure test. However, some discoloration of the E-Type Metal Cup seals was observed. This discoloration was a change in the metal finish from a nice copper hue to a darker brown hue and was observed in about 14 of the 70 E-Cups.

\subsubsection{Cobra Seal Test to Failure}

A special test was performed on six Cobra Seals to determine at which point they would fail under intense radiation conditions and what the failure mode would be. These six Cobra Seals were independent of the 70 units used in all the standard tests. Since the ${ }^{60}$ Co High Dose Facility was the only facility capable of the extremely high exposure rates needed, it was used to conduct this special test. The Cobra Seals were exposed in increments up to a total of 2M-rads gamma radiation. The Cobra Seals were inspected and the images recorded after each incremental exposure. The total exposures after each increment were $10 \mathrm{~K}, 30 \mathrm{~K}, 50 \mathrm{~K}, 100 \mathrm{~K}, 150 \mathrm{~K}, 200 \mathrm{~K}, 300 \mathrm{~K}, 500 \mathrm{~K}, 1000 \mathrm{~K}$, and $2000 \mathrm{~K}(2 \mathrm{M})$ rads. The recorded images after $500 \mathrm{~K}$ rads total exposure were sufficiently darkened to be considered failed since the image could not be used to compare against the reference image to determine a match. The progressive degradation in the seal image can be seen in Figure 10. The Cobra Seal body also turned 
color from clear to gold, although this did not detract from the ability to visually inspect the seal for signs of tampering. The color change of the seal body can be seen in Figure 11.

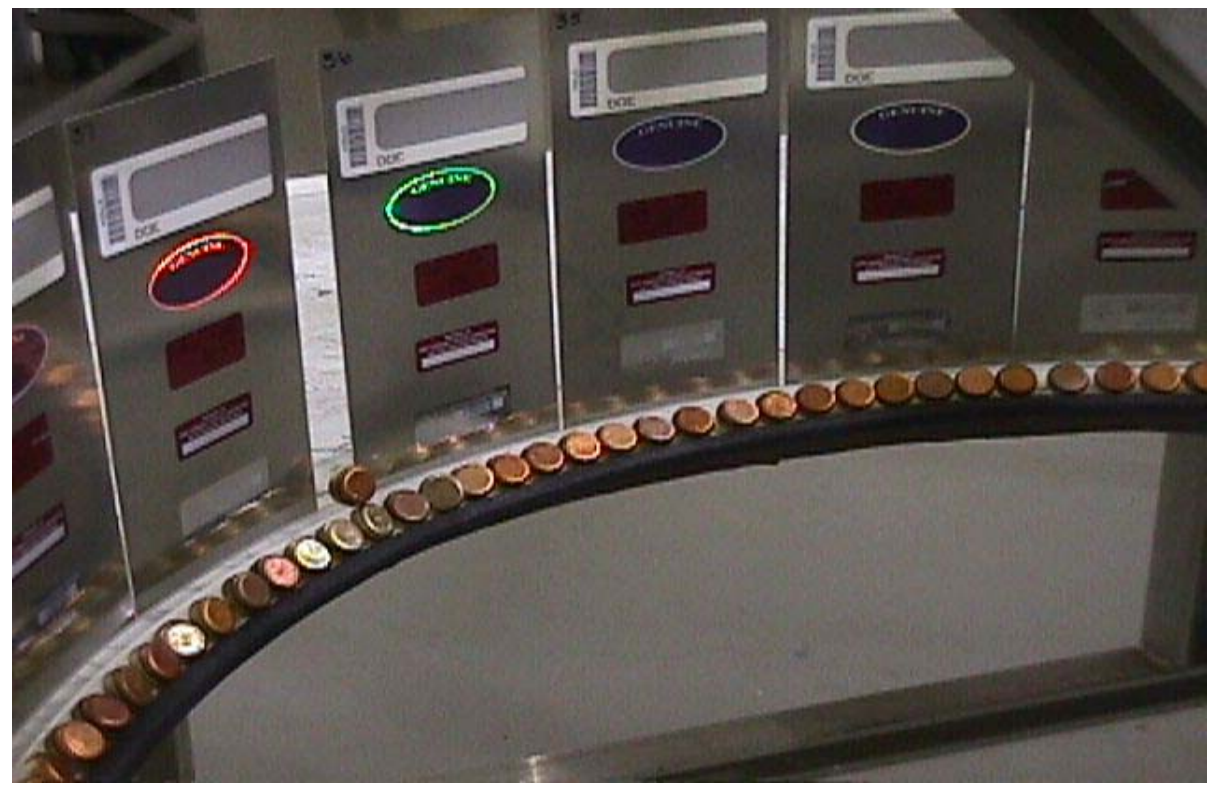

Figure 8. Adhesive Seals and E-Cups Around the South Exposure Station

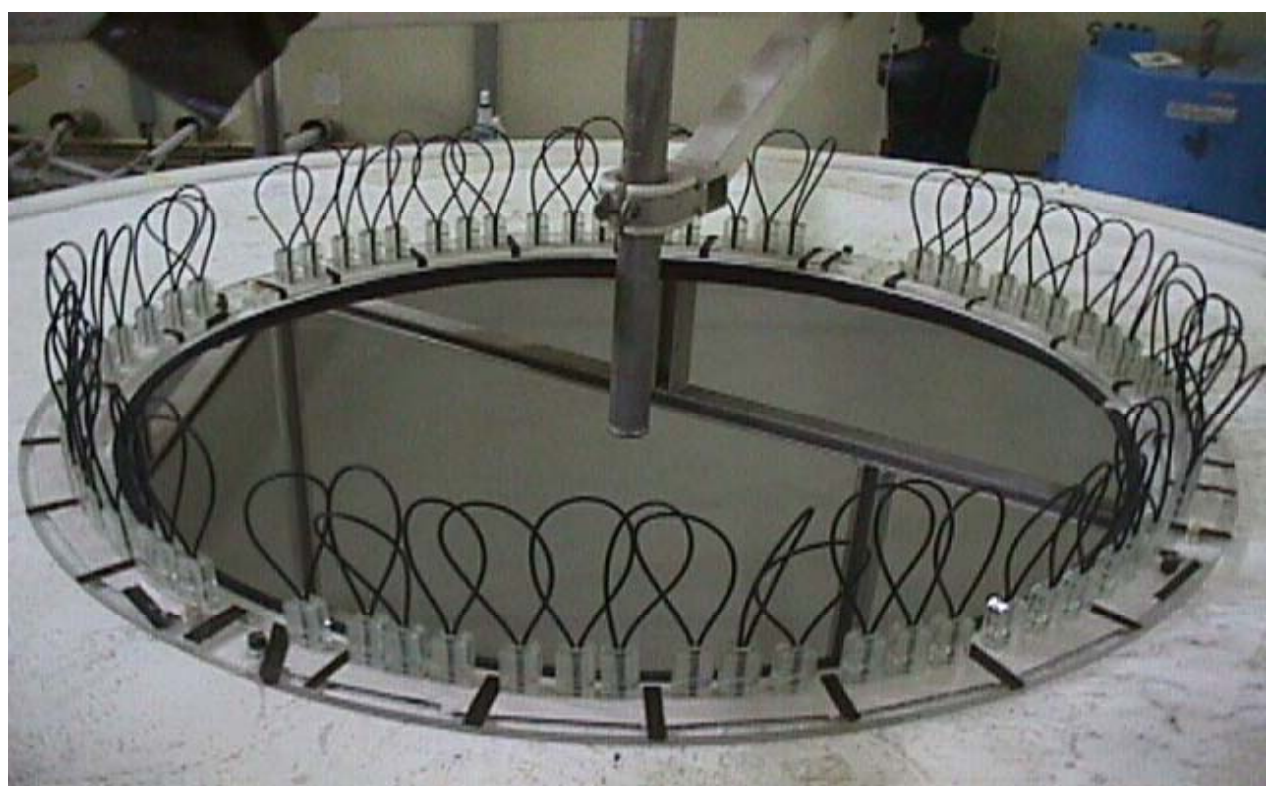

Figure 9. Cobra Seals Around the South Exposure Station 


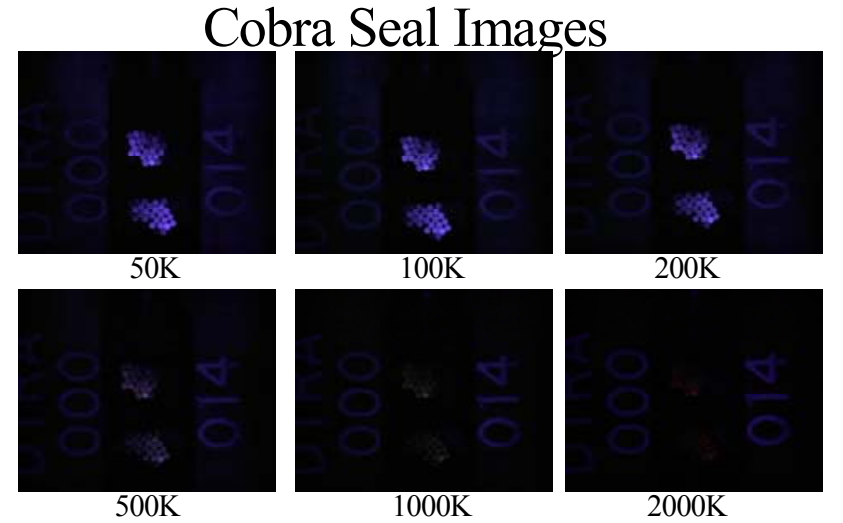

Figure 10. Cobra Seal Images After 50K, 100K, 200K, $500 \mathrm{~K}, 1 \mathrm{M}$, and $2 \mathrm{M}$ Rads

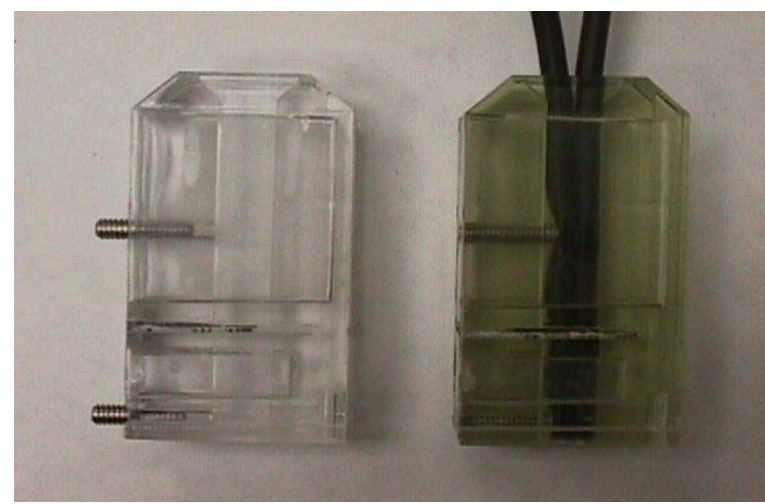

Figure 11. Cobra Seal Body Unexposed and Exposed to 500,000 Rads

\subsection{Temperature and Humidity Testing}

The TIDs were tested over the temperature range of $-20^{\circ} \mathrm{C}$ to $50^{\circ} \mathrm{C}$ and the relative humidity range of $20 \%$ to $90 \%$ relative humidity $(\mathrm{RH})$. Tests to determine the performance of the various TIDs under conditions of cold temperatures, dry heat, wet heat, variations of cold to hot temperatures involving both low and high relative humidity, and variations of the above were performed as outlined in IES 60068-2.

\subsubsection{Thermal Testing}

The TIDs to be tested thermally were initially placed in the Russell environmental chamber at ambient temperature for cold temperature testing (Figure 12). This test began at 15:20 on August 24th, 2000. The temperature was varied from ambient to $-20^{\circ} \mathrm{C}$ in 1 hour. The temperature remained at $-20^{\circ} \mathrm{C}$ $\pm 3^{\circ} \mathrm{C}$ for 96 hours. At 15:20 on August $28^{\text {th }}$, the chamber was returned to ambient temperature, and each specimen was removed and checked to determine its condition. All TIDs appeared to be in good condition following this first round of thermal testing. The E-Tags were all read with the reader to verify their continued readability. The Cobra Seals were all photographed. Each E-Cup was checked and found in good condition. All adhesive seals were also checked, and several exhibited a small amount of bubbling. None, however, appeared to have failed.

Each TID specimen was then returned to the environmental chamber for dry heat testing. They entered the environmental chamber at ambient temperature at 10:00 on September $1^{\mathrm{st}}$. The temperature was varied from ambient to $50^{\circ} \mathrm{C}$ in 15 minutes. The temperature remained at $50^{\circ} \mathrm{C} \pm 2^{\circ} \mathrm{C}$ for 96 hours. On September $5^{\text {th }}$ at 10:15, the chamber was turned off, and the temperature was allowed to return to ambient temperature. Again, each specimen was removed and examined. All TIDs remained in good condition with no evidence of failure. The copper bottoms of E-Cups 51,65,67, 104, and 105 did, however, exhibit a color change at the end of this test. The E-tags were all checked and found to be readable, and the Cobra seals were photographed. 


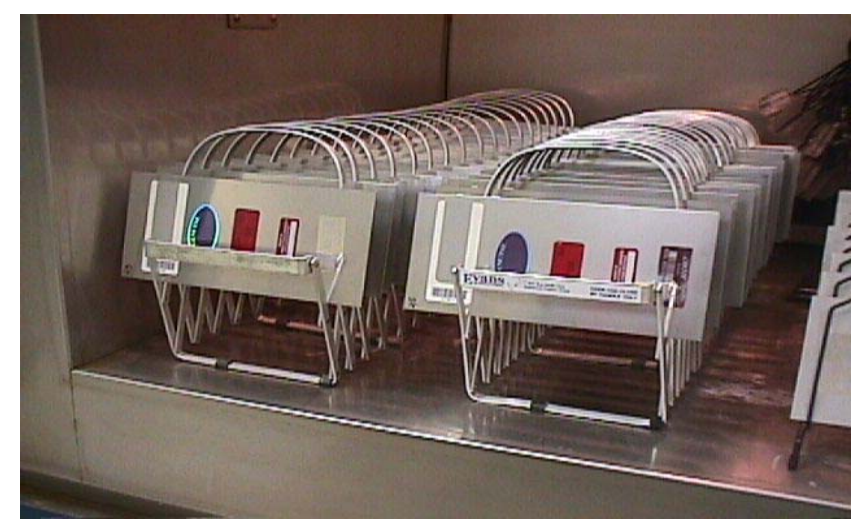

Figure 12. Adhesive Seals Inside Environmental Chamber

On September $14^{\text {th }}$ at 12:00, the TIDs were returned to the environmental chamber to undergo thermal and humidity stressing. This test procedure is in conformity with the IEC 68-2-56 standard. Each specimen entered the chamber under ambient conditions. At that point, the temperature was lowered from ambient to $5^{\circ} \mathrm{C} \pm 2^{\circ} \mathrm{C}$, and the humidity was increased to $90 \% \pm 5 \% \mathrm{RH}$. After 48 hours on September $16^{\text {th }}$ at $12: 00$ noon, the temperature was changed to $40^{\circ} \mathrm{C} \pm 2^{\circ} \mathrm{C}$, and the test continued at that temperature and RH for the next 48 hours. On September $18^{\text {th }}$ at 12:20 pm, the temperature in the chamber was decreased to $5^{\circ} \mathrm{C} \pm 2^{\circ} \mathrm{C}$ again with the $\mathrm{RH}$ remaining at $90 \% \pm 5 \%$ and remained at that temperature and $\mathrm{RH}$ for the next 24 hours. On September $19^{\text {th }}$, the temperature was again changed back to $50^{\circ} \mathrm{C} \pm 2^{\circ} \mathrm{C}$ and $90 \% \pm 5 \% \mathrm{RH}$, remaining under those conditions for the next 24 hours. The test continued in this manner, changing between $5^{\circ} \mathrm{C} \pm 2^{\circ} \mathrm{C}$ and $50^{\circ} \mathrm{C} \pm 2^{\circ} \mathrm{C}$ for two more cycles, at which time the length of time between each cycle was reduced to 12 hours for the next 48 hours until the last lowtemperature cycle. The total duration of this temperature and humidity test was 10 days, as illustrated in Figure 13. At the completion of the test, the chamber returned to ambient temperature and $\mathrm{RH}$ and the TIDs were removed from the chamber and inspected. All TIDs reacted very well to the temperature and humidity tests. There were no failures, and even the small amount of bubbling that had appeared in some of the adhesive seals previously had disappeared during this phase of the testing process. All of the Cobra seals were photographed, the E-Tags were read, and a visual assessment was given to the E-Cups and the adhesive seals.

\subsection{Mechanical Testing}

The purpose of the mechanical test series was to address the types of physical stresses TIDs might experience enroute to the FMSF and during the process of handling the material containers and of applying the seals to the containers and the storage nests. With the exception of the shock tests of adhesive seals, all of the TIDs used in the mechanical test sequences had previously undergone radiation, temperature, and humidity testing. 


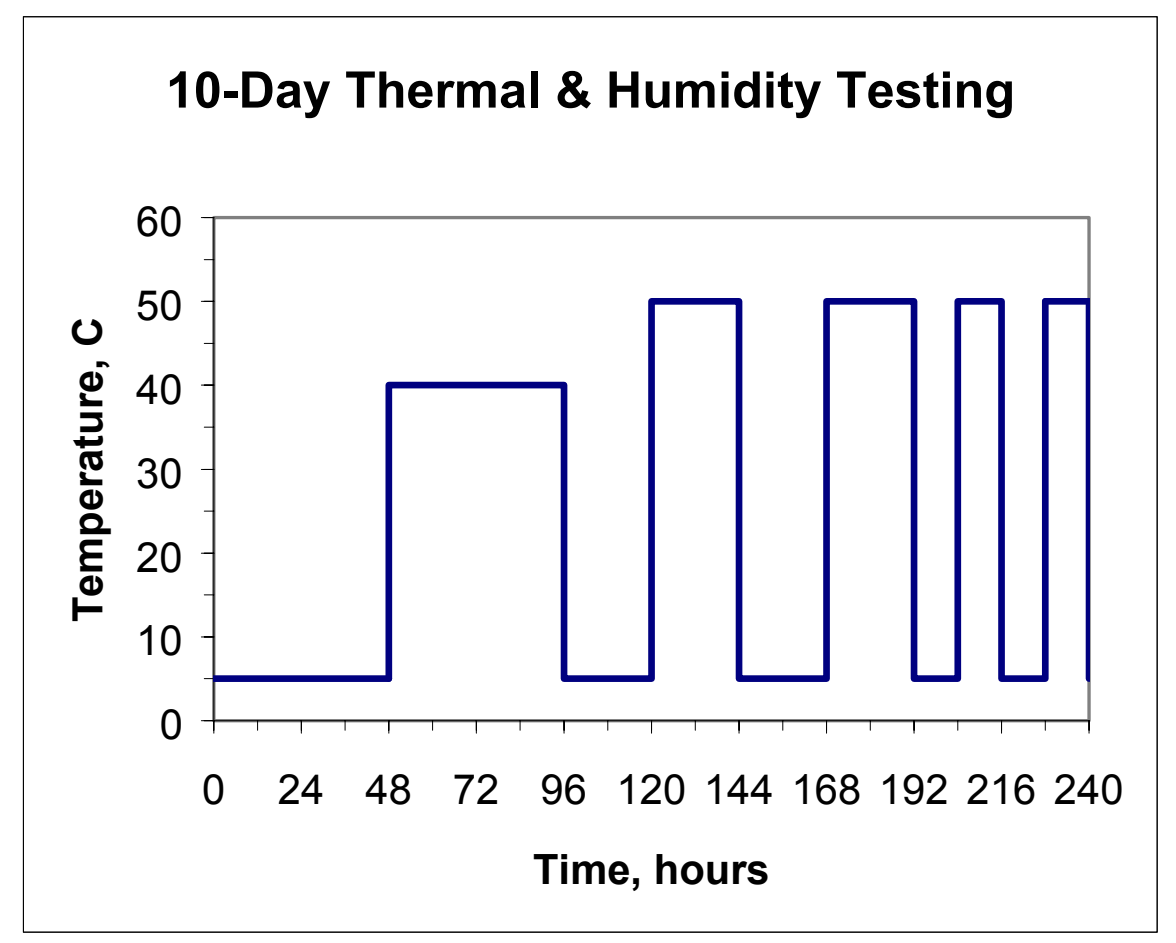

Figure 13. 10-Day Thermal and Humidity Testing

\subsubsection{Pull Testing for Loop-Type Seals}

For the pull test, each TID wire was suspended above from a hook with a 50-lb weight hanging below. The force of the 50-lb weight was applied to the TID by slowly lowering the weight support platform until it was hanging freely, suspended by the TID wire or cable, then timed for 60 seconds, as illustrated in Figure 14.

Following the pull tests, the E-Cups and E-Tags were visually inspected. One E-Cup and one E-Tag failed this test due to the wire slipping out of the grommet inside the seal as the weight was initially applied.

The Cobra seals were imaged before and after and given a visual inspection following the pull testing. Initially, it was thought that all Cobras passed the pull test; however, after reviewing the images taken following the pull test, it was revealed that three Cobras failed this test due to the cable being retracted very slightly into the seal body (Figure 15). 


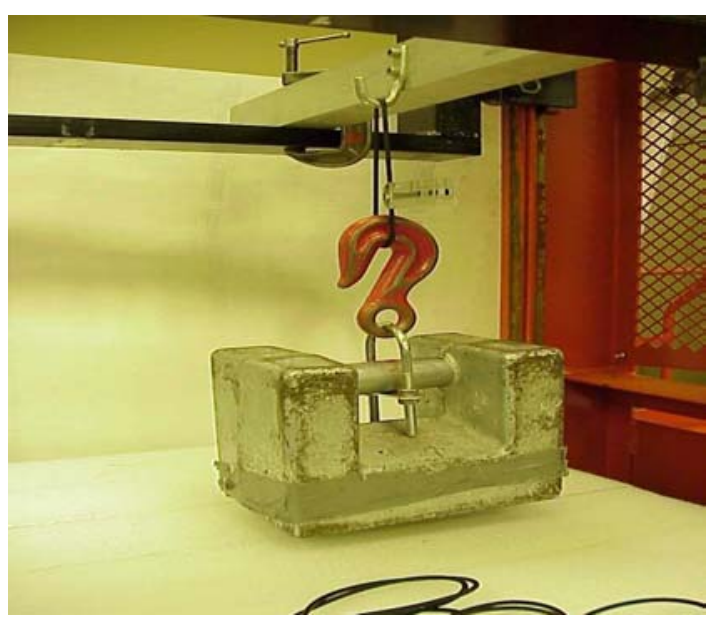

Figure 14. Loop Seal 50-1b Pull Test
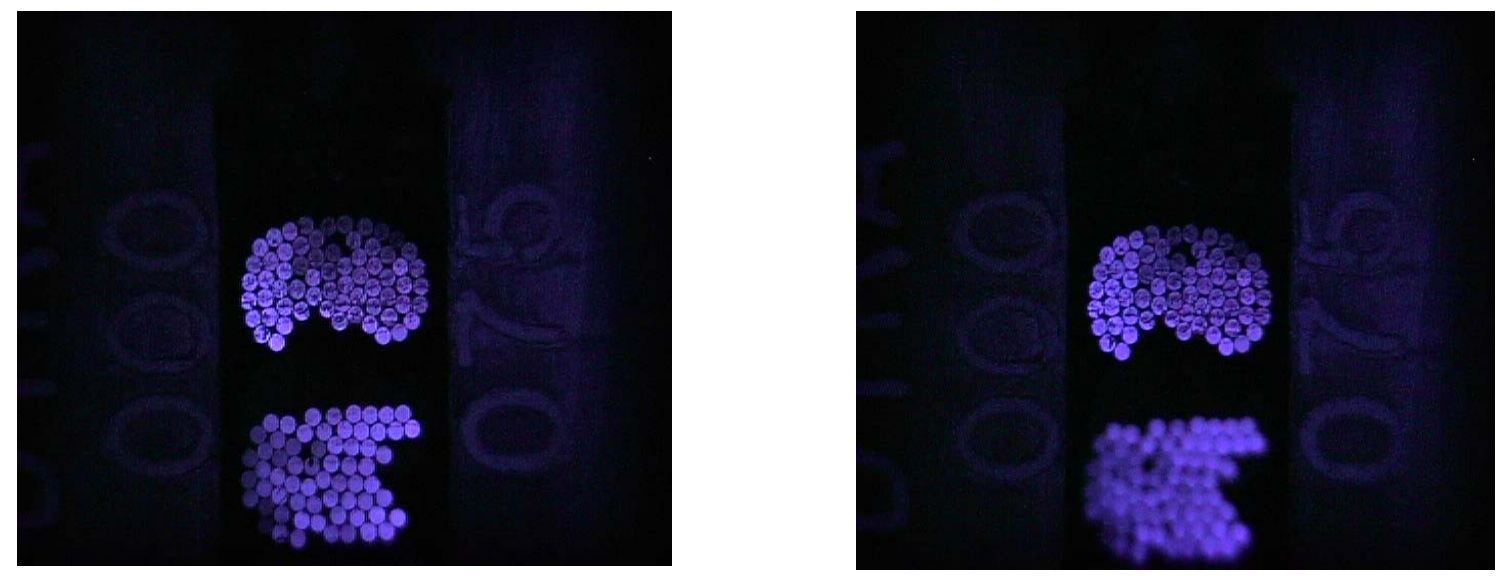

Figure 15. Cobra Seal \# 75 Before and After Pull Test

It was noted earlier in this report that during the initial preparation of the Cobra seals for the test program, the manufacturer-supplied Monotool failed mechanically, resulting in only one of the two cutting blades being lowered onto the fiber-optic cable. (All three of the failed Cobras exhibited this anomaly, plus several of those that passed the pull test. This problem was not obvious until the before and after pull test images were compared.)

\subsubsection{Drop Testing for Loop-Type Seals}

For the drop testing, the loop seals were connected from above in the same manner as the pull test. The lower section of the loop was hooked to a cord that was attached to a 5-lb weight. The weight was raised $30.5 \mathrm{~cm}$ (12 in.), and then dropped, simulating a sudden jerk on the loop. This is illustrated in Figure 16. 

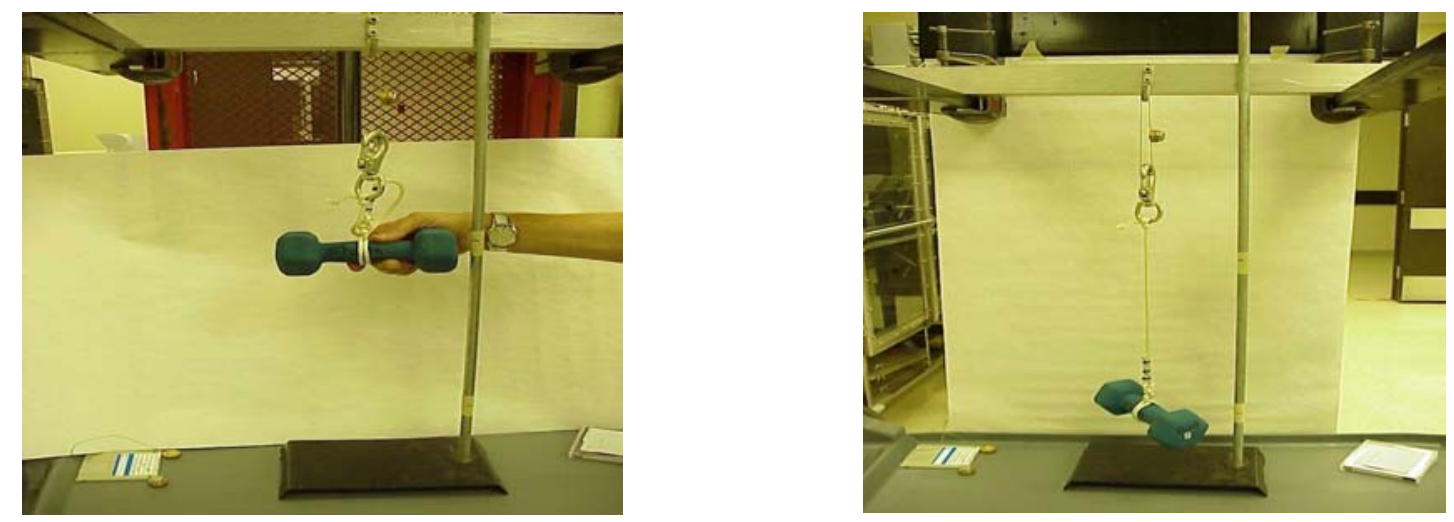

Figure 16. Loop Seal 5-1b Drop Test

A substantial number of failures were encountered during this test phase. Seven E-Tags and nine E-Cups failed the test when the grommet inside the seal that connected the wires failed. The failed E-Tags are shown in Figure 17. In addition, almost all of the E-Cups and E-Tags showed evidence of tearing or elongation of the wire holes (Figure 18).

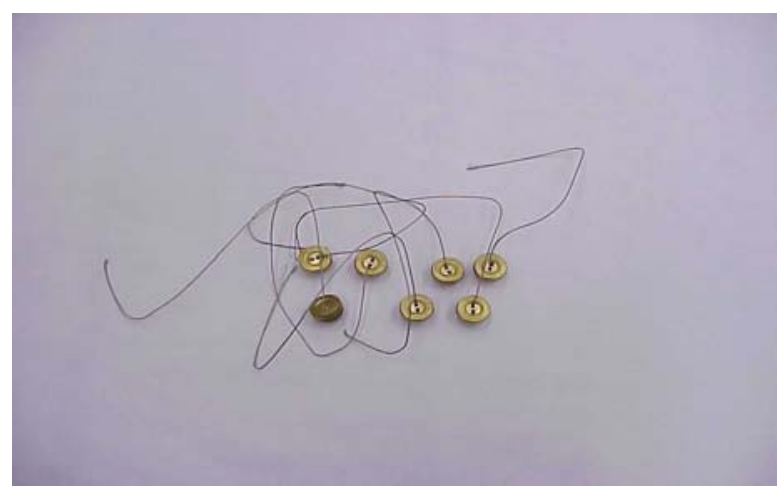

Figure 17. E-Tag Drop Test Failures

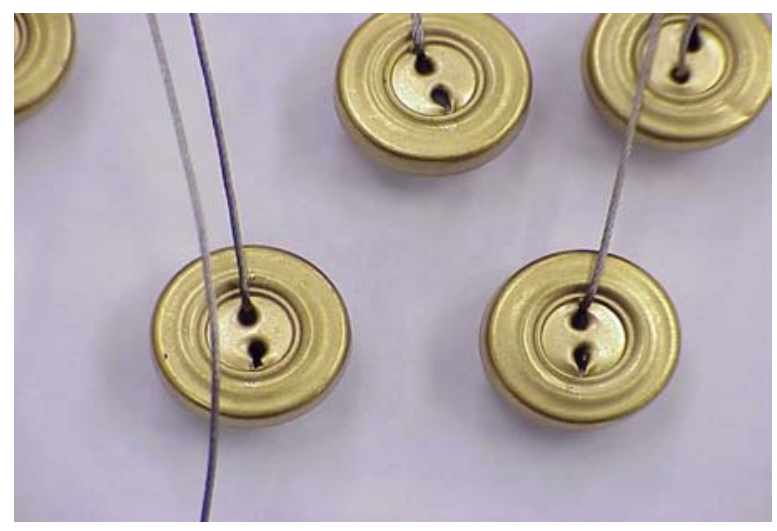

Figure 18. Elongation of E-Cup Wire Holes

A post-test analysis of the E-Cups and E-Tags was conducted to determine the possible cause of the failures. The metal cups were cut open along the sides to facilitate photography of the E-Cups for comparison with photographs taken before the test program began. During the initial preparation of the E-Cups and E-Tags, two types of grommets were used; one type uses a single hole, and the other type uses two holes as shown in Figure 19. The single-hole grommets were measurably more difficult to crimp. All of the E-Cup and E-Tag failures had utilized the single-holed grommet.

There were no new failures of the Cobra seals during the drop testing. 


\subsubsection{Vibration Testing for Loop-Type Seals}

Vibration tests were conducted on the loop seals, primarily to determine robustness during shipping and handling. A test apparatus designed for this purpose enabled a variety of conditions to be simulated.

The seals were attached to the test bench (Figure 20) and vibrated as a group for 20-minute periods at 10, 30, and $60 \mathrm{~Hz}$. Ten $\mathrm{Hz}$ appeared to be a close simulation of what a container would experience on the back of a truck driving over unimproved roads. For example, 20 minutes of vibrations at $10 \mathrm{~Hz}$ represented 12,000 bounces at $4.4 \mathrm{~g}$ acceleration. Thirty $\mathrm{Hz}$ might represent the vibration that would be experienced during high-speed rail travel. Sixty Hz provided a buzz-type effect. The amplitude of the vibrations resulted in accelerations of 4.4 to $6.0 \mathrm{~g}$.

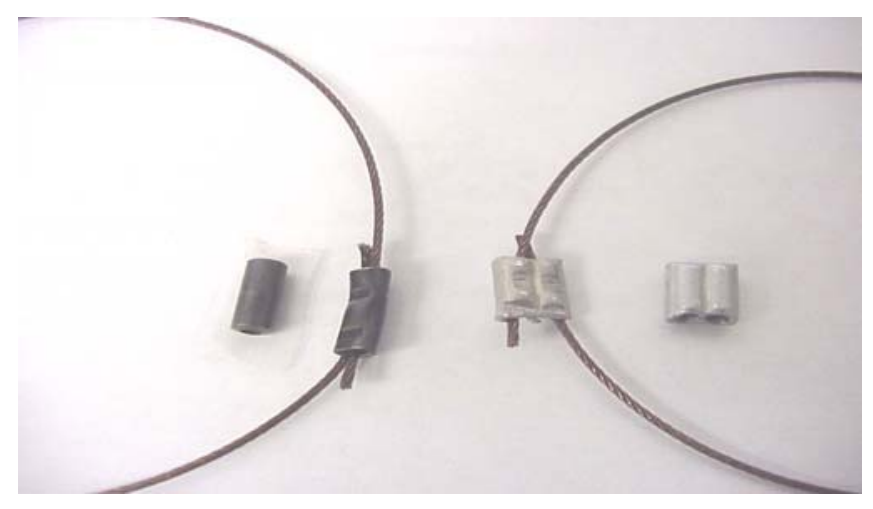

Figure 19. Single and Double-Holed Grommets

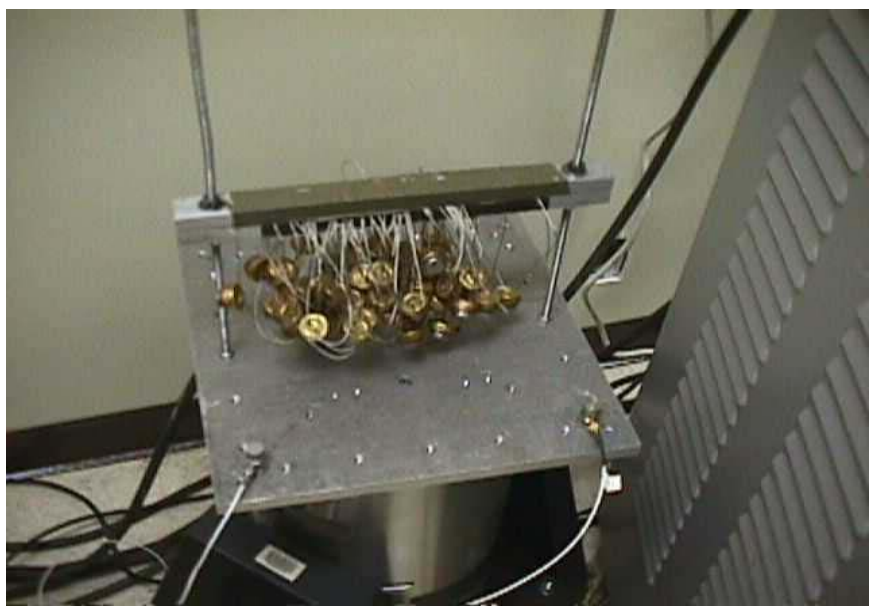

Figure 20. E-Cup Vibration Testing

\subsubsection{Vibration Testing of Adhesive Seals}

It was determined that simply vibrating the adhesive seals on the test plates would not provide a realistic challenge simulating handling and transportation scenarios that the adhesive seals might encounter in the Mayak regime. Therefore, six of each type of adhesive seal that had not undergone previous radiation, temperature, and humidity exposures were used on a 113.56-L (30-gal) drum that was 
certified by the Department of Transportation for the transport and storage of fissile material in the United States. To replicate the inertia factor of a loaded AT-400R fissile material container, lead weights were added to the internal container to bring the weight to approximately $200 \mathrm{lb}$, the same weight that a loaded container would normally weigh. The container was sanded to remove some rust and corrosion. The seals were attached to the drum on the locking ring around the top. A minimum cure time of 72 hours was allowed for the adhesive seals. The drum was then securely fastened to a large $122 \mathrm{~cm} \mathrm{x}$ $122 \mathrm{~cm}$ (48 in. $\mathrm{x} 48$ in.) vibration test platform (Figure 21).

There were no apparent failures for any of the E-Cup, E-Tag, and Cobra seals.

The test parameters were limited by the physical capabilities of the test platform. The initial vibration run was conducted for 30 minutes at $15 \mathrm{~Hz}$ and $1-\mathrm{g}$ acceleration. The effect was very similar to that of a truck with very stiff springs. After the initial test period, the seals were inspected, paying close attention to the small gaps around the locking ring. All seals looked very good.

The counter weights were changed on the vibration table, which allowed a small frequency change to $11.5 \mathrm{~Hz}$ at 1 -g acceleration for another test period of 30 minutes. This small frequency change created a slightly rougher ride. Approximately 5 minutes into this second vibration run, it was noticed that one Koehler-Gibson seal came loose at the bottom. A second Koehler-Gibson failed approximately 20 minutes into this second run. Figure 22 is a close-up showing how the seals came loose on the drum surface.

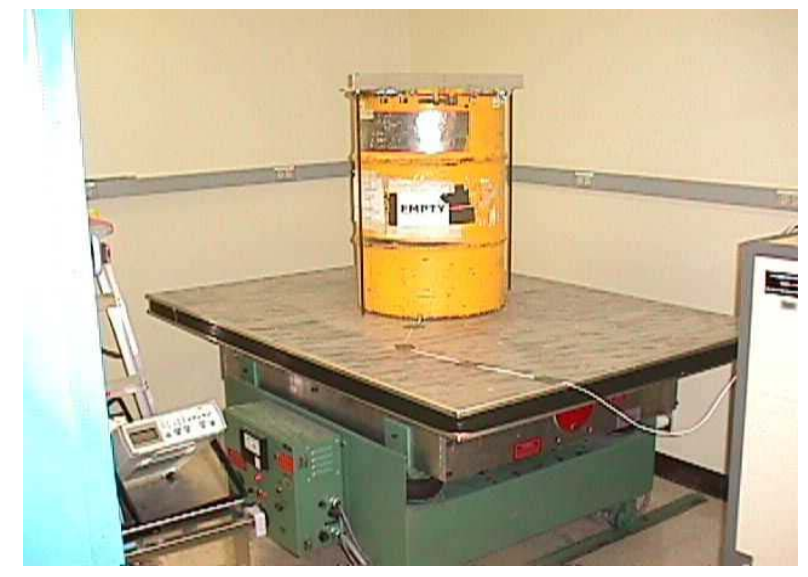

Figure 21. Vibration Test Platform

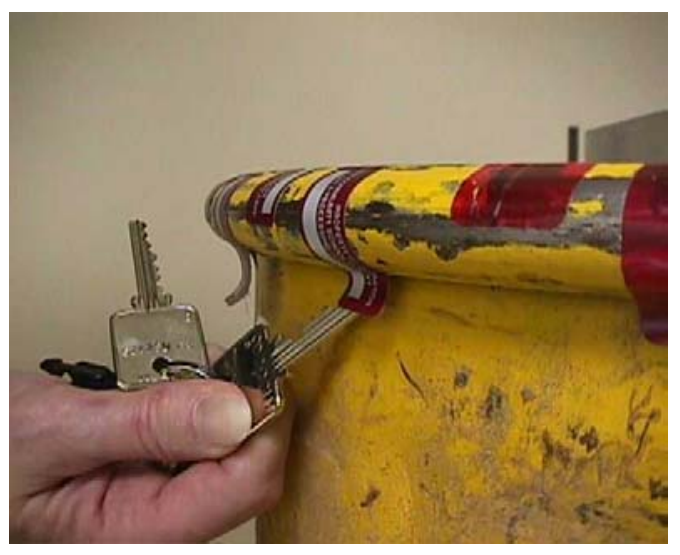

Figure 22. Koehler-Gibson Test Failures

Two of six Koehler-Gibson seals came loose at the drum-locking rim interface. All other adhesive seals showed no effect.

\subsubsection{Mechanical Shock Test}

Mechanical shock testing was restricted to adhesive seals only since there are no scenarios for loop seals where shock testing is necessary. The mechanical shock test was specified to test the adhesive seals attached to a container dropped from a height of 1 meter to a hard surface as shown in Figure 23. For this test, the same 113.56-L (30-gal) drum configuration that was used in the adhesive seal vibration testing was utilized. The test drum was again weighted to $200 \mathrm{lb}$ to duplicate the inertia effect of a loaded AT- 
400R container. The barrel was dropped once onto a hard surface. Pre and post inspection of the adhesive seals indicated no failures.

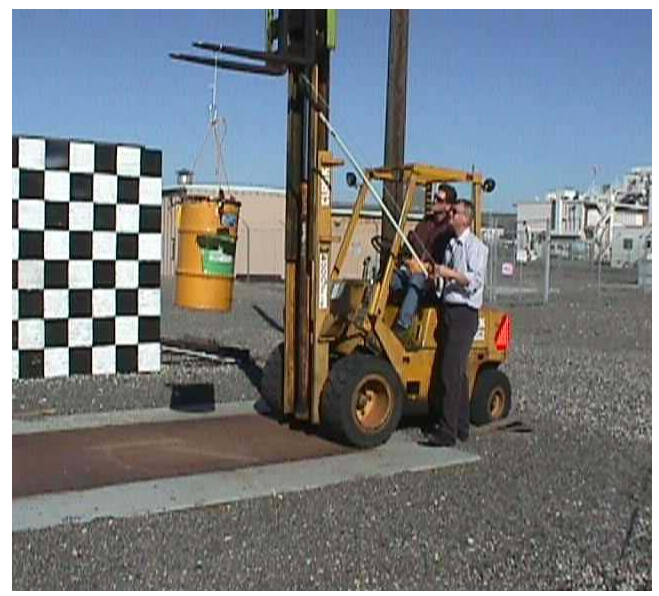

Figure 23. 113.56 L (30-Gal) Drum ready for Mechanical Shock Test

\subsubsection{Abrasion Testing of Adhesive Seals}

For the abrasion test, the metal plates containing the adhesive seals were secured to the floor with adhesive tape (Figure 24). Sandpaper was glued to the bottom of the outside of a box in which a 5-1b weight had been placed. A rope was secured to the box, and the box was slowly dragged over each portion of the plates three times. Each seal was then evaluated for abrasion. Some minor scuffing was noted on most of the MIKOH and Alcan seals. There was also some evidence of scuffing on a few of the 3M TED seals, but no scuffing was found on the Koehler-Gibson or 3M Confirm Tamper Tapes. None of the adhesive seals showed any evidence of tampering as a result of the abrasion test.

\subsection{Electromagnetic Testing}

This test phase was intended to determine TID response to a variety of non-ionizing radiation artificially generated by appropriate test equipment. The only TID type in this test program that might have concerns in these regimes would be the E-Tag and E-Tag reader. The digital camera for the Cobra reader was considered for testing, but not tested due to lack of spares and the high cost of a potential failure. It is also unlikely that the Cobra reader would be subjected to any unusual or non-ambient electromagnetic exposure. For purposes of this testing, the E-Tag numbers were read electronically on a portable computer by a special reader and reader software before and after each phase of electromagnetic exposure. Where practical, the E-Tag readers were also exposed to the same electromagnetic fields. For the same concerns as the Cobra digital camera, the portable computer was not intentionally exposed to artificially generated fields.

\subsubsection{Sensitivity to Interfering Magnetic Fields}

The E-Tag samples were tested using a Walker Scientific 3-axis Helmholtz coil apparatus. The tests were conducted using a 10-gauss AC magnetic field (Figure 25). The E-Tags were bundled together and 
exposed to the magnetic field for 1 hour. All E-tags were successfully read electronically during and following this test.

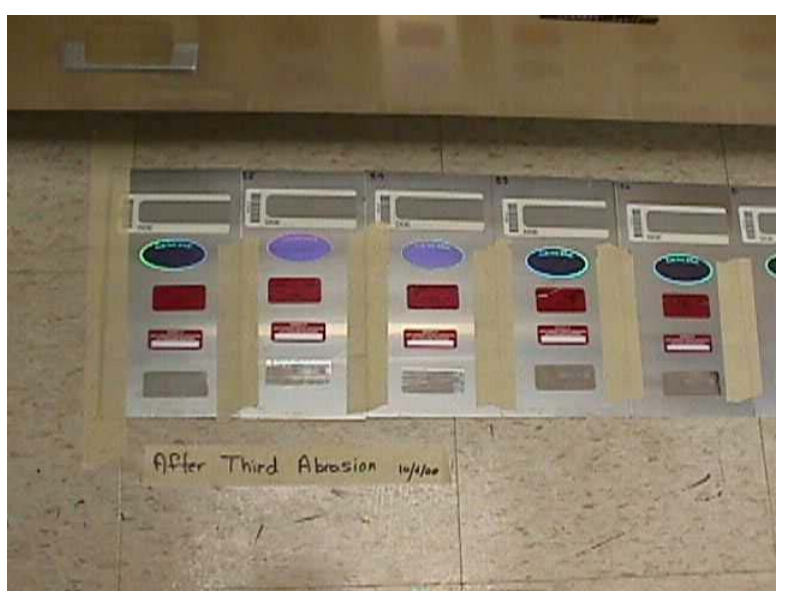

Figure 24. 113.56-L (30-Gal) Drum ready for Mechanical Shock Test

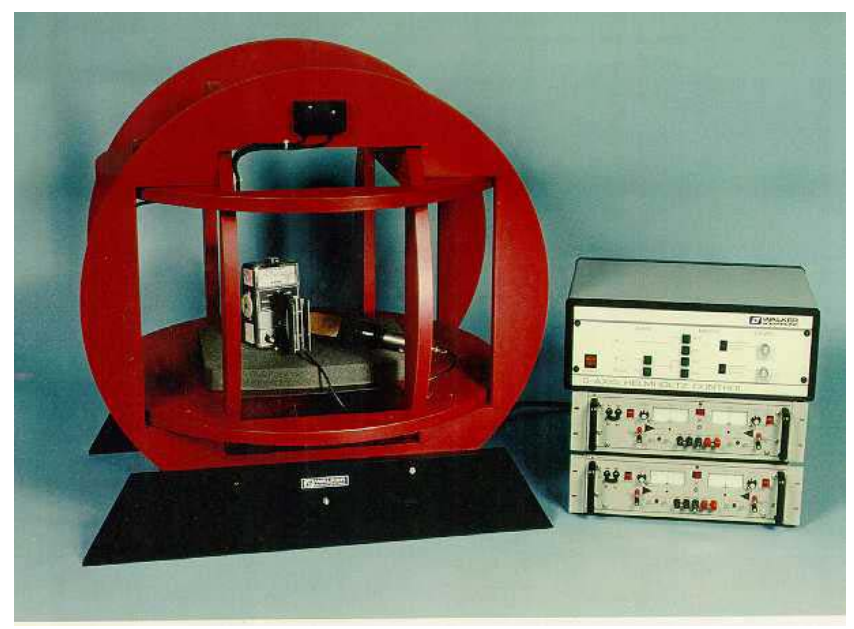

Figure 25. Magnetic Test Chamber

\subsubsection{Sensitivity to Interfering Microwave Fields}

The samples of E-Tags were exposed to microwave fields using a Holaday Industries microwave exposure chamber (Figure 26). The exposures were performed at $2450 \mathrm{MHz}$ with a power density of $10 \mathrm{~mW} / \mathrm{cm}^{2}(\sim 200 \mathrm{~V} / \mathrm{m}$ electric field strength). The exposure frequency is identical to the one used in commercial microwave ovens. The E-Tags were bundled together, placed in the chamber, and exposed to the microwave field for 1 hour; then they were read by the electronic reader. All E-Tags were read electronically with no observed failures.

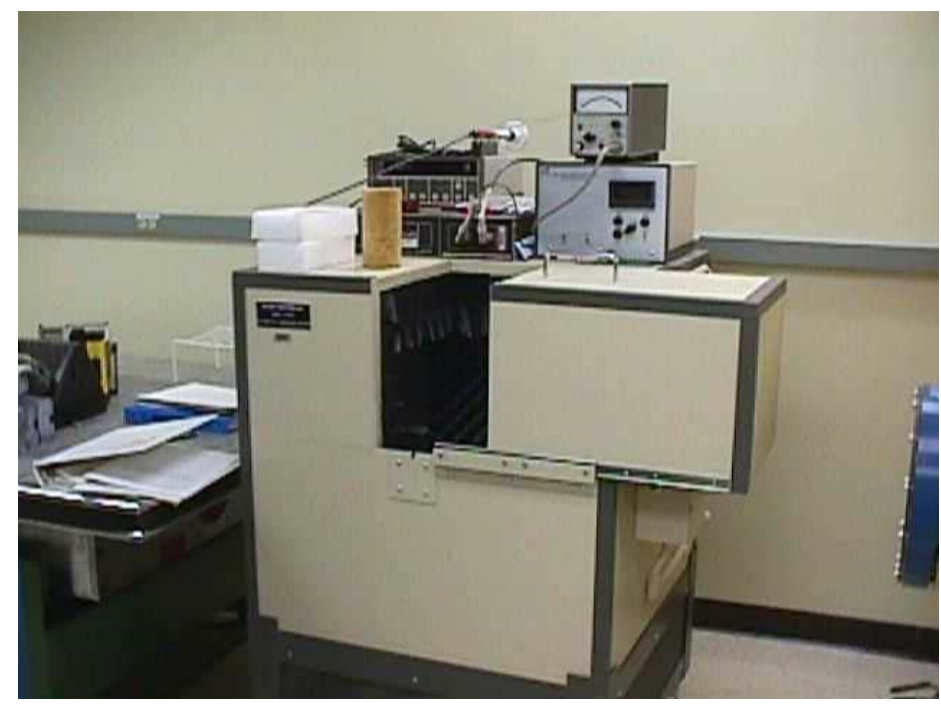

Figure 26. Microwave Test Chamber 


\subsubsection{Sensitivity to Radiofrequency Interference}

The samples were tested using a transverse electromagnetic (TEM) cell manufactured by Amplifier Research. The testing was conducted over a frequency range of $500 \mathrm{kHz}$ to $375 \mathrm{MHz}$. The maximum electric-field strength available at any given frequency was used during the testing. The electric fields encountered in most "real-world" locations will be far below the levels used during this testing. Radiofrequency emitters found in this frequency range include:

1) AM Broadcast (530 to $1710 \mathrm{kHz}$ )

2) Short-wave Broadcast (1 MHz-27 MHz)

3) Citizens Band Radios (27 MHz)

4) Public Service Radio Communications/Cordless Phones (30 to $54 \mathrm{MHz}$ )

5) TV Stations (54 to $72 \mathrm{MHz}$ )

6) FM Broadcast ( 88 to $108 \mathrm{MHz}$ )

7) Aircraft Communications (108 to $132 \mathrm{MHz}$ )

8) Public Service Radio Communications (137 to $174 \mathrm{MHz}$ )

Table 5 summarizes the frequencies and field-strength levels used during this testing. Two separate amplifiers were used with the TEM cell to generate the radio-frequency field. One amplifier covered the frequency range $500 \mathrm{kHz}$ to $200 \mathrm{MHz}$ and provided a maximum electric field strength of $525 \mathrm{~V} / \mathrm{m}$. A second amplifier covered the 250 - to $375-\mathrm{MHz}$ frequency range and produced a maximum electric field strength of $325 \mathrm{~V} / \mathrm{m}$. Electric field strength was verified using a Holaday broadband electric field probe.

Table 5. Radiofrequency Test Parameters

\begin{tabular}{|r|c||}
\hline \hline Frequency & Maximum Electric Field Strength (V/m) \\
\hline $500 \mathrm{kHz}$ & 525 \\
\hline $1 \mathrm{MHz}$ & 525 \\
\hline $10 \mathrm{MHz}$ & 525 \\
\hline $50 \mathrm{MHz}$ & 525 \\
\hline $100 \mathrm{MHz}$ & 525 \\
\hline $150 \mathrm{MHz}$ & 525 \\
\hline $200 \mathrm{MHz}$ & 525 \\
\hline $250 \mathrm{MHz}$ & 325 \\
\hline $300 \mathrm{MHz}$ & 325 \\
\hline $375 \mathrm{MHz}$ & 325 \\
\hline
\end{tabular}

An initial test was performed using a single E-Tag. The E-Tag was exposed at each frequency for approximately 1 minute. In the initial test, the E-Tag was interrogated using the E-Tag reader inside and outside of the radio-frequency field generated by the TEM cell. In the final test, a complete sample of E-Tags was exposed at the same time to each frequency (for 1 minute) and interrogated later using the E-Tag reader (Figure 27). 
In the initial test using one E-Tag, no radio-frequency interference was noted. The E-Tag was readable after radio-frequency exposure. The E-Tag was also read successfully when the E-Tag reader probe was inside the TEM cell. The subsequent test of the complete sample of E-Tags did not reveal any failed samples.

\subsubsection{Sensitivity to Electrostatic Discharge}

The E-Tag samples were tested for sensitivity to electrostatic discharge (ESD) using an ESD generator manufactured by Andy Hish \& Associates (Model ESD 255). The samples were exposed to discharges ranging from $2.5 \mathrm{kV}$ to $25 \mathrm{kV}$ as illustrated in Figure 28. The ESD generator was designed to produce controlled static-discharge events similar to those produced by a human touching a grounded surface with a metal object (such as a key).

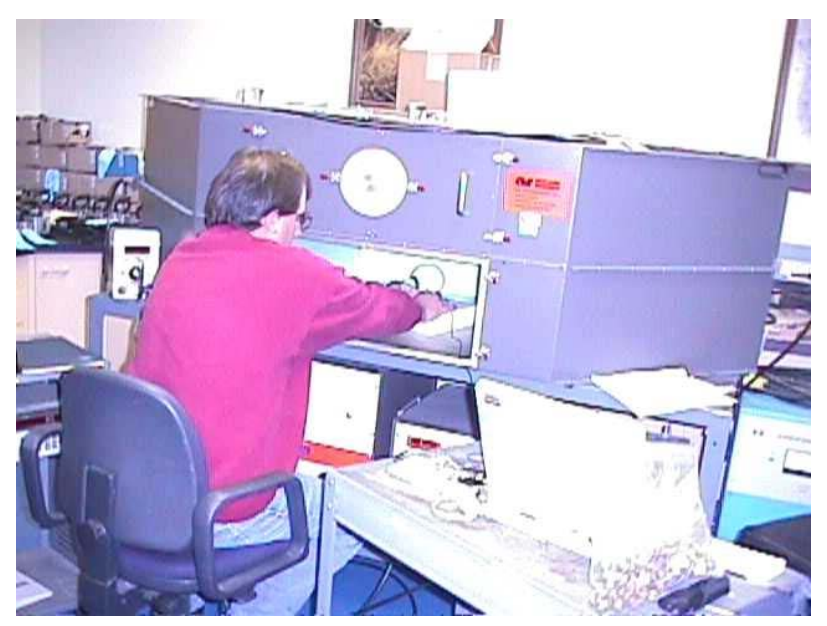

Figure 27. E-Tag Testing in RF Chamber

The following are examples of potential ESDs in real world situations:

- Walking across a carpet: $1.5 \mathrm{kV}$ to $35 \mathrm{kV}$

- Walking over untreated vinyl floor: $0.25 \mathrm{kV}$ to $12 \mathrm{kV}$

- Working at a bench top: $0.7 \mathrm{kV}$ to $6 \mathrm{kV}$

- Picking up a common plastic bag from a bench top: $1.2 \mathrm{kV}$ to $20 \mathrm{kV}$.

A small sample of E-Tags was exposed from $2.5 \mathrm{kV}$ to $25 \mathrm{kV}$ in $2.5-\mathrm{kV}$ intervals. A series of 50 dis charges was delivered at each voltage. After a "failure threshold" was determined, a sample of 10 E-Tags was exposed at $17.5 \mathrm{kV}$. Again, 50 discharges were administered to each E-Tag.

During the initial testing, one E-Tag failed at $12.5 \mathrm{kV}$, two failed at $17.5 \mathrm{kV}$, and two did not fail. Of the $10 \mathrm{E}$-Tags exposed at $17.5 \mathrm{kV}, 8$ failed and 2 passed. A failure of the E-Tag simply means that the electronic reader was unable to interpret the serial number. There was no observed physical damage to the E-Tags, and the serial numbers could be easily read visually. Because of the high failure rate for the electrostatic discharge testing, it was elected to preserve the remaining samples and conclude that the E-Tags are susceptible to failure after exposure to nominal electrostatic discharges. 


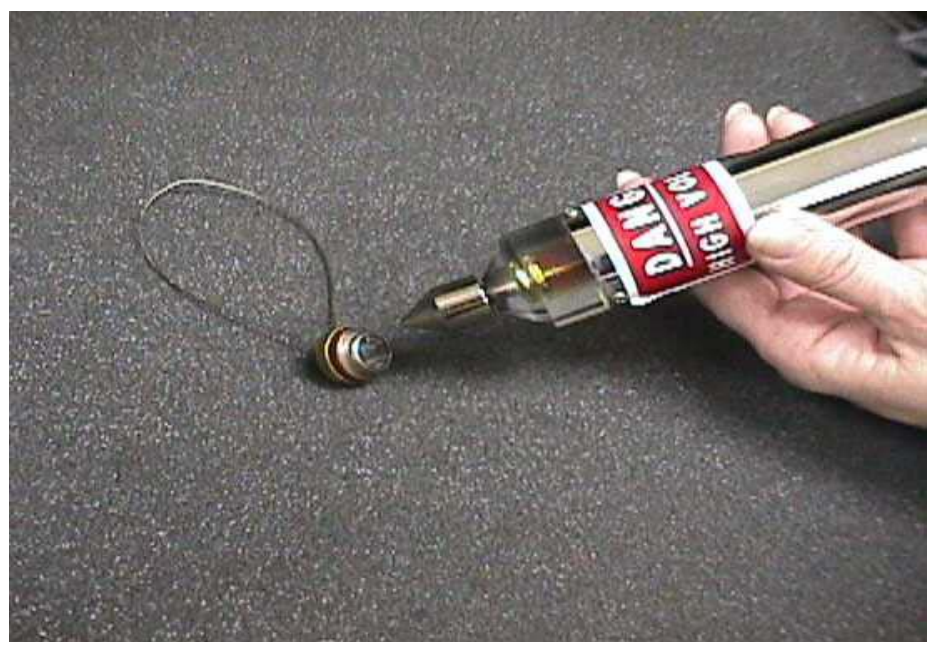

Figure 28. E-Tags During ESD Testing 


\subsection{Summary and Recommendations}

The TID environmental-performance testing campaign resulted in several types of failures in a number of TIDs during the latter phases of testing. The test phases and their failure rates are summarized below. Based on these failures, patterns of failure were determined during post-mortem analysis. In one case, specifying the use of only one type of supporting hardware could have eliminated failures. In another case, failures could have been avoided by checking the TID at the time of installation for evidence of incomplete sealing. Future failures can be minimized through comprehensive operator training and detailed installation and inspection procedures. A pattern of failure for a particular TID following a specific test may be cause to judge that TID unsuitable for use in the Mayak FMSF. However, other factors besides failure rates are taken into consideration when recommending the best overall TID for a given application.

All TIDs tested performed without failure during the ionizing radiation testing. A special radiation exposure test to failure for the Cobra seals showed that they are useable at more than 200 times the expected 50-year lifetime radiation dose at the Mayak FMSF. Therefore, the expected ionizing-radiation environment at Mayak FMSF is not a factor influencing the choice of TIDs tested under this program.

Temperature and humidity testing, appropriate to the conditions at the Mayak FMSF, also resulted in no significant issues for any of the TIDs tested. The expected temperature and humidity conditions inside the Mayak FMSF do not create unacceptable conditions for the choice of TIDs tested in this program.

The mechanical test program resulted in significant failures of the wire loop seals, primarily due to the type of grommet used. Three cobra seals also failed this test phase, due to incomplete installation caused by a defective Monotool. With careful selection and application of grommet type (2-hole), and proper redesign of the nest cover and mating assembly, wire-loop seals could be used on the nest covers at Mayak. However, without a redesign of the nest cover and mating assembly, they cannot be used. Cobra seals, when applied using the manufacturer-provided Monotool, are appropriate for applications at Mayak. The adhesive seals performed well as a group, with minor exceptions, and should be useable wherever they are not exposed to severe mechanical abrasion or shearing stress.

Electromagnetic testing showed that the E-Tags were quite susceptible to failure when exposed to static discharges; otherwise, there were no significant issues in this phase of the testing. The staticdischarge failure only affected the capability to read the E-Tag serial number electronically, and such a failure mode is not considered significant. Electromagnetic environments likely to be encountered at the Mayak FMSF do not pose significant issues for the use of the tested TIDs. However, there is still the need to take normal precautions with sensitive equipment such as cameras and computers.

Based on the results of the TID tests and evaluations performed, the following conclusions and recommendations are provided for each of the TID roles at the Mayak FMSF:

1) The Fissile Material Containers - The possible options for sealing the lid of the AT-400R are adhesive seals and the two wire-loop seals, the E-Type Cup Metal Seal, and the E-Tag Mechanical Seal. Due to the length of time the fissile material containers may be in storage between inspections, adhesive seals are not recommended. Out of the two remaining choices, we recommend the E-Type 
Cup Metal seal with the internal scribing over the E-Tag due to the expected obsolescence of the E-Tag's associated electronic reader and software. This choice is also consistent with IAEA practice, and commercial seal suppliers are readily available. This recommendation must be balanced by vulnerability assessments.

2) The Storage Nest Covers - Significant operational issues with regard to TIDs on the storage nest covers were encountered. A mockup of the nest top and cover clearly showed that none of the tested loop seals could be effectively used for this application, given the initial nest cover and matingassembly design. PNNL research staff proposed design-modification recommendations that could provide for the secure use of IAEA standard loop-type seals on the nest cover. However, it is our understanding that these modifications cannot be made due to significant cost and schedule impacts with respect to the entire FMSF construction. It is our judgment at this time that no IAEA or internationally accepted TID will adequately work on the storage nest cover. This puts an additional burden on the entire facility-monitoring scheme. Because there is still a Mayak Transparency Protocol requirement for a TID on the storage nest cover, we believe this issue needs to be resolved by bringing together a DTRA and multi-laboratory team to explore all possible options, such as modifications of existing technologies or combining two or more technologies or even evaluating non-standard technologies.

3) Monitoring Equipment - Monitoring and inspection equipment, such as recording devices and video cameras and associated data-storage media that can be stored in containers, is easily protected using the tested TID technologies. We recommend the use of Cobra seals for securing containers used to store sensitive monitoring equipment between inspections. Adhesive seals may be used during inspections for short-term applications, such as securing equipment during lunch breaks, and for the storage of less-sensitive items. This precedent has already been set for INF inspections where equipment was stored at the point of entry in the Russian Federation and secured using shrink wrap, Cobra seals, and adhesive seals. We recommend the 3M Confirm Tamper Tape for an adhesive seal because of its additional security features. The 3M Confirm Tamper Tape also turned out to be very resistant to abrasion and mechanical shock. 


\subsection{References}

Azzalin G, F Van Paelmel, and C Korn. 1996. Thermal and Humidity Tests on PNL Tamper Tape Seals, Technical Note No.I.96.39, Joint Research Centre, European Commission, Ispra, Italy.

Demetriuou J, K Gartner, and G Laszlo. 1993. Qualification Test Specification for Non-destructive Assay (NDA) and Containment \& Surveillance (C\&S) Equipment, STR-284, International Atomic Energy Agency, Vienna, Austria.

International Electrotechnical Commission (IEC). 1988. Environmental Testing Part 1, IEC-68-1, Geneva Switzerland.

International Electrotechnical Commission (IEC). 1990. Environmental Testing Part 1, IEC-68-1, Geneva Switzerland.

Korn C and K Gartner. 1996. Qualification Testing of New Safeguards Equipment, Test Procedure V.1.2, Task EUR A 00860, European Commission Joint Research Centre, Ispra, Italy, International Atomic Energy Agency, Vienna, Austria.

Military Test Standard. 1995. Environmental Test Methods and Engineering Guidelines, MIL-STD810E. Wright-Patterson Air Force Base, Ohio.

Sandia National Laboratory (SNL). 1993. Tamper-Indicating Devices and Safeguards Seals Evaluation Test Report, Volume I. Sandia Report, SAND93-1726/1, Albuquerque, New Mexico.

Sandia National Laboratory (SNL). 1995. Tamper-Indicating Devices and Safeguards Seals Evaluation Test Report, Volume II. Sandia Report, SAND93-1726/2, 1995, Albuquerque, New Mexico.

TRW. 2000. Test report for Tags and Tamper Indicating Devices (TIDs). TRW Report Data Item 006. Albuquerque, New Mexico.

Wright BW, CW Wright, A. Bunk, BA Metz, and GE Pickett. 1995a. Accelerated Aging Studies and Environmental Stability of Prototype Tamper Tapes. PNL-10562, Pacific Northwest National Laboratory, Richland, Washington.

Wright BW, CW Wright, RW Smith, GE Pickett, AR Bunk, M Luttinger, and BA Metz. 1995b. Development of Rapid-Set Adhesive and Application Systems for Tamper Tape Seals. PNL-10693, Pacific Northwest National Laboratory, Richland, Washington. 
Appendix A

Environmental Test Equipment Specifications 


\title{
Appendix A: Environmental Test Equipment Specifications
}

\author{
ANSI Testing Laboratory \\ Pacific Northwest National Laboratory (PNNL) has an American National Standards Institute \\ (ANSI) Testing Laboratory located in Richland, Washington, that is part of PNNL's Radiological \\ Standards and Calibration Laboratory. This fully operational laboratory is designed to characterize the \\ effects of temperature, pressure, humidity, vibration, acceleration, ac power, and \\ microwave/RF/electromagnetic fields on instrument/equipment response. General specifications of the \\ equipment are listed below:
}

\begin{tabular}{|c|c|}
\hline Environmental Chamber & $-68^{\circ} \mathrm{C}$ to $177^{\circ} \mathrm{C}, 5 \%$ to $95 \% \mathrm{RH}$ \\
\hline Mechanical Vibration Table & $\begin{array}{l}8 \text { to } 60 \mathrm{~Hz}, \max \text {. acceleration }=3.2 \mathrm{~g} \text {, max. test } \\
\text { load }=680 \mathrm{~kg}\end{array}$ \\
\hline $\begin{array}{l}\text { High Frequency, High } \\
\text { Acceleration Vibration Table }\end{array}$ & $\begin{array}{l}10 \text { to } 60 \mathrm{~Hz} \text {, max. acceleration }=10 \mathrm{~g} \text {, } \max \text {. } \\
\text { test load }=45 \mathrm{~kg}\end{array}$ \\
\hline $\begin{array}{l}\text { Mechanical Shock Testing } \\
\text { Apparatus }\end{array}$ & $\begin{array}{l}\text { Max. acceleration }=3000 \mathrm{~g}, \text { max. test load }= \\
90.7 \mathrm{~kg}\end{array}$ \\
\hline Magnetic Field Exposure System & $\mathrm{DC}$ and $60 \mathrm{~Hz}, 0$ to 10 Gauss \\
\hline $\begin{array}{l}\text { Military Standard } 462 \text { Radio } \\
\text { Frequency Exposure System }\end{array}$ & $\begin{array}{l}0.3 \text { to } 35 \mathrm{MHz} \text {, maximum field strength }=100 \\
\mathrm{v} / \mathrm{m}\end{array}$ \\
\hline
\end{tabular}




\section{Appendix B}

CD-ROM - Pictures of Testing, Cobra Seal Images, and Laboratory Record Book 


\section{Appendix B: CD-ROM - Pictures of Testing, Cobra Seal Images, and Laboratory Record Book}

The Appendix B CD-ROM is available upon request. Please contact Jennifer E. Tanner (phone: 509375-6626; email: jennifer.tanner@pnl.gov) at Pacific Northwest National Laboratory, Richland, Washington. 
PNNL-13599

\section{Distribution List}

No. of

Copies

\section{OFFSITE}

4 Sandia National Laboratories

PO Box 5800

Albuquerque, NM 87185

Attn:

Denny Mangan

MS 1213

John Matter

Doug Smathers

MS 1361

MS 0455

Dianna Blair

MS 1213

2 Oak Ridge National Laboratory

P.O. Box 2008

Oak Ridge, TN 37831

Attn:

Chris Pickett

MS 7312

Alex Reidy

MS 7312

2 Lawrence Livermore National Laboratory 7000 East Ave.

Livermore, CA 94550-9234

Attn:

Arden Dougan

Wayne Current

6 Los Alamos National Laboratory

PO Box 1663 MS E540

Los Alamos, New Mexico, 87545

Attn:

Greg Sheppard

Jeff Martin

Roger Johnston

Anthony Garcia

Larry Avens

Jim Doyle

MS E541

MS K575
No. of

Copies

OFFSITE

2 Pantex

PO Box 30020

Amarillo, TX 79120

Attn:

Leigh Bratcher

Van Collins

1 Tom Shea

Trilateral Initiative Office

Department of Safeguards

International Atomic Energy Agency

IAEA-SM-367

Vienna International Centre

PO Box 100

Wagramer Strasse 5

A-1400 Vienna, Austria

1 Paul Mann

DOE Albuquerque Operations

PO Box 5400

Albuquerque, NM 87185-5400

4 DOE NNSA

1000 Independence Ave SW

Washington D.C. 20585

Attn:

Kurt Siemon

Michele Smith

Paul Irwin

John Murphy

1 SAIC

6350 Walker Lane Suite 110

Alexandria, VA 22310

Attn:

John McNeilly

Distr. 1 
PNNL-13599

No. of

Copies

\section{OFFSITE}

1 SAIC

2109 Air Park Road, SE

Albuquerque, NM 87106

Attn:

Ron Weitz

2 The Defense Threat Reduction Agency 8725 John J. Kingman Drive, MSC 6201 Fort Belvoir, VA 22060-6201

Attn:

Thomas Rutherford

Hunter Lutinski

2 The Defense Threat Reduction Agency

Technology Applications Division

(DTRA/TDA)

6801 Telegraph Road

Alexandria, VA 22310

Attn:

Thomas Dunham

Dexter Simmons

1 Mary Scott

The Defense Threat Reduction Agency

45045 Aviation Drive

Dulles International Airport

Dulles, VA 20166-7517

3 Department of Defense OSD

Room 5A730

The Pentagon

Washington, D.C.

Attn:

T. R. Koncher

Jim Reid
No. of

Copies

\section{ONSITE}

1 U.S. Department of Energy-Richland Operations

Glenn Konzek A6-35

16 Pacific Northwest National Laboratory

$\begin{array}{ll}\text { Halvor Undem } & \text { K8-46 } \\ \text { Jennifer Tanner } & \text { K3-55 } \\ \text { James Fuller } & \text { K8-02 } \\ \text { Deborah Dickman } & \text { K8-46 } \\ \text { James Griggs } & \text { K8-46 } \\ \text { Sharon Pratt } & \text { P8-01 } \\ \text { Paul Tomeraasen } & \text { P7-03 } \\ \text { Bruce Roberts } & \text { K8-46 } \\ \text { Michael Newman } & \text { K8-46 } \\ \text { John Smoot } & \text { K8-46 } \\ \text { Roger Sharp } & \text { K8-16 } \\ \text { Matthew Smith } & \text { K3-55 } \\ \text { Roy Lundgren } & \text { K8-46 } \\ \text { Paul Stansbury } & \text { K3-54 } \\ \text { Richard Kouzes } & \text { P8-20 } \\ \text { Bruce Geelhood } & \text { P8-08 }\end{array}$

